\title{
North American extreme temperature events and related large scale meteorological patterns: a review of statistical methods, dynamics, modeling, and trends
}

\author{
Richard Grotjahn $^{1} \cdot$ Robert Black $^{2} \cdot$ Ruby Leung $^{3} \cdot$ Michael F. Wehner $^{4} \cdot$ \\ Mathew Barlow $^{5}$ - Mike Bosilovich ${ }^{6}$ - Alexander Gershunov ${ }^{7}$. \\ William J. Gutowski Jr. ${ }^{8}$ John R. Gyakum ${ }^{9}$ Richard W. Katz ${ }^{10}$. \\ Yun-Young Lee ${ }^{1} \cdot$ Young-Kwon Lim ${ }^{11} \cdot$ Prabhat $^{4}$
}

Received: 7 August 2014 / Accepted: 4 May 2015 / Published online: 22 May 2015

(c) The Author(s) 2015. This article is published with open access at Springerlink.com

\begin{abstract}
The objective of this paper is to review statistical methods, dynamics, modeling efforts, and trends related to temperature extremes, with a focus upon extreme events of short duration that affect parts of North America. These events are associated with large scale meteorological patterns (LSMPs). The statistics, dynamics, and modeling sections of this paper are written to be autonomous and so can be read separately. Methods to define extreme events statistics and to identify and connect LSMPs to extreme temperature events are presented. Recent advances in statistical techniques connect LSMPs to extreme temperatures through appropriately defined covariates that supplement more straightforward analyses. Various LSMPs, ranging from synoptic to planetary scale structures, are associated with extreme temperature events. Current knowledge about the synoptics and the dynamical mechanisms leading to the associated LSMPs is incomplete. Systematic studies
\end{abstract}

Richard Grotjahn

grotjahn@ucdavis.edu

1 Atmospheric Science Program, Department of L.A.W.R., University of California Davis, One Shields Ave., Davis, CA 95616, USA

2 School of Earth and Atmospheric Sciences, Georgia Institute of Technology, 311 Ferst Drive, Atlanta, GA 30332-0340, USA

3 Pacific Northwest National Laboratory, Richland, WA 99352, USA

4 Lawrence Berkeley National Laboratory, Berkeley, CA 94720, USA

5 University of Massachusetts Lowell, Lowell, MA 01854, USA

6 NASA GSFC Global Modeling and Assimilation Office, Greenbelt, MD 20771, USA of: the physics of LSMP life cycles, comprehensive model assessment of LSMP-extreme temperature event linkages, and LSMP properties are needed. Generally, climate models capture observed properties of heat waves and cold air outbreaks with some fidelity. However they overestimate warm wave frequency and underestimate cold air outbreak frequency, and underestimate the collective influence of low-frequency modes on temperature extremes. Modeling studies have identified the impact of large-scale circulation anomalies and land-atmosphere interactions on changes in extreme temperatures. However, few studies have examined changes in LSMPs to more specifically understand the role of LSMPs on past and future extreme temperature changes. Even though LSMPs are resolvable by global and regional climate models, they are not necessarily well simulated. The paper concludes with unresolved issues and research questions.

Climate, Atmospheric Science and Physical Oceanography (CASPO) Division, Scripps Institution of Oceanography, University of California San Diego, La Jolla, CA 92093, USA

8 Department of Geological and Atmospheric Sciences, Iowa State University, Ames, IA 50011, USA

9 Department of Atmospheric and Oceanic Sciences, McGill University, Montreal, QC H3A 0B9, Canada

10 Institute for Mathematics Applied to Geosciences, National Center for Atmospheric Research, Boulder, CO 80307, USA

11 NASA Goddard Space Flight Center, Global Modeling and Assimilation Office, Goddard Earth Sciences Technology and Research/I.M. Systems Group, 8800 Greenbelt Rd, Greenbelt, MD 20771, USA 
Keywords Large scale meteorological patterns for temperature extremes $\cdot$ Heat waves $\cdot$ Hot spells $\cdot$ Cold air outbreaks · Cold spells - Statistics of temperature extremes · Dynamics of heat waves - Dynamics of cold air outbreaks Dynamical modeling of temperature extremes $\cdot$ Statistical modeling of extremes $\cdot$ Trends in temperature extremes

\section{Introduction to temperature extremes}

Temperature extremes have large societal and economic consequences. While many heat waves are short-lived, longer events can have a large economic cost. Cold air outbreaks (CAOs) tend to be short-lived but carry large economic losses. Timing of the CAOs can be more important than the minimum temperatures of the freeze; during 4-10 April 2007 low temperatures across the South caused \$2B in agricultural losses since many crops were in bloom or had frost sensitive buds or nascent fruit (Gu et al. 2008). The event also exemplifies how monthly means can be misleading: April 2007 average temperatures were near normal. In short, both hot spells (HSs) and CAOs have great societal importance and they are short-term events that do not necessarily appear in monthly mean data.

This report focuses on short-term (5-day or less) extreme temperature events occurring in some part of North America. Temperature extremes considered in this paper include both short-term hottest days (warm season) and CAOs (winter and spring) as these have the greatest impacts. Such events, both observed and simulated, have received considerable attention (including research papers, e.g. Meehl and Tebaldi 2004; and active websites: http://www.esrl. noaa.gov/psd/ipcc/extremes/, http://www.ncdc.noaa.gov/ extremes/cei/, and http://gmao.gsfc.nasa.gov/research/ subseasonal/atlas/Extremes.html). However, the emphasis here is on the less well understood context for the extreme events. Our primary context is the large-scale meteorological patterns (LSMPs) that accompany these extreme events.

Temperature extreme events are usually linked to large displacements of air masses that create a large amplitude wave pattern (here called an LSMP). LSMPs have a spatial scale bigger than mesoscale systems but smaller than the near-global scale of some modes of climate variability. The LSMP often has some portion that is superficially similar to a blocking ridge, so a blocking index can be an LSMP indicator (Sillmann et al. 2011). Extreme events have also been linked to circulation indices like the North Atlantic Oscillation (NAO) (Downton and Miller 1993; Cellitti et al. 2006; Brown et al. 2008; Kenyon and Hegerl 2008; Guirguis et al. 2011) the Madden-Julian Oscillation (MJO) (Moon et al. 2011) and El Niño/Southern Oscillation (ENSO) (Downton and Miller 1993; Higgins et al. 2002;
Carrera et al. 2004; Meehl et al. 2007; Goto-Maeda et al. 2008; Kenyon and Hegerl 2008; Alexander et al. 2009; Lim and Schubert 2011). However, LSMPs are likely distinct from climate modes for several reasons. First, named climate modes such as the NAO are common modes of variability, whereas the LSMP is presumably as rare as the associated extreme event. Second, climate modes occur on a longer time scale than the LSMPs for the short-term events focused upon in this article. However, it is possible that an extreme event might occur when a climate mode has transient extreme magnitude or is amplified in association with another low frequency phenomenon. Third, tested LSMP patterns are not that similar to climate modes. In correlating eight NOAA teleconnection patterns (http://www.cpc. ncep.noaa.gov/data/teledoc/telecontents.shtml) and California LSMPs and in assessing the PNA contribution to last winter's extreme cold in eastern North America (neither shown here), we do not find notable contribution from such modes. Several studies identified the LSMPs associated with specific extreme hot events (Grotjahn and Faure 2008; Loikith and Broccoli 2012) and CAO events (Konrad 1996; Carrera et al. 2004; Grotjahn and Faure 2008; Loikith and Broccoli 2012). Parts of these LSMPs tend to be uniquely associated with the corresponding extreme weather and those parts have some predictability (Grotjahn 2011).

The LSMPs for extreme events are not fully understood for different parts of North America. Also, local processes: topography, soil moisture, etc. play key roles but there is a knowledge gap in how well climate models simulate the LSMPs as well as these local processes and how the local and global modes interact with LSMPs. Bridging these knowledge gaps will reduce the uncertainty of future projections and drive model improvements.

Now is an opportune time to summarize critical issues and key gaps in understanding temperature extremes variability and trends because: (1) it is not known if current climate models used for future projections are producing extremes via the correct dynamical mechanisms, which directly impacts confidence in projections, and (2) knowledge of the LSMPs can improve downscaling (statistical or dynamical) by focusing attention on large scale patterns that are fundamental to the occurrence of the extreme event. Conversely, global models that do not reproduce the magnitude or duration of extreme temperature events accurately may still capture the correct LSMPs and facilitate downscaling. Finally, there is now sufficient preliminary work and growing interest to make a summary valuable.

From the LSMP context, the objectives of this review are surveys of: relevant statistical tools for extreme value analysis (Sect. 2), synoptic and dynamical interactions between LSMPs and other scales from local to global (Sect. 3), model simulation issues (Sect. 4), trends in these 
Table 1 Some temperature related ETCCDI indices (Sillmann et al. 2013a)

\begin{tabular}{|c|c|c|}
\hline ETCCDI index name & Semi-formal definition & Plain English \\
\hline TX90p & $\begin{array}{l}\text { The percentage of days when the high temperature is } \\
\text { greater than } 90 \% \text { of those in reference period }\end{array}$ & Hot days \\
\hline TX10p & $\begin{array}{l}\text { The percentage of days when the high temperature is less } \\
\text { than } 10 \% \text { of those in reference period }\end{array}$ & Cold days \\
\hline TN90p & $\begin{array}{l}\text { The percentage of days when the low temperature is greater } \\
\text { than } 90 \% \text { of those in reference period }\end{array}$ & Hot nights \\
\hline TN10p & $\begin{array}{l}\text { The percentage of days when the low temperature is less } \\
\text { than } 10 \% \text { of those in reference period }\end{array}$ & Cold nights \\
\hline TXx & $\begin{array}{l}\text { Monthly or seasonal maximum of daily maximum } \\
\text { temperature }\end{array}$ & Hottest day \\
\hline TXn & $\begin{array}{l}\text { Monthly or seasonal minimum of daily maximum } \\
\text { temperature }\end{array}$ & Coldest day \\
\hline $\mathrm{TNx}$ & $\begin{array}{l}\text { Monthly or seasonal maximum of daily minimum } \\
\text { temperature }\end{array}$ & Hottest night \\
\hline $\mathrm{TNn}$ & $\begin{array}{l}\text { Monthly or seasonal minimum of daily minimum } \\
\text { temperature }\end{array}$ & Coldest night \\
\hline HWDI & Heat Wave Duration Index & Length of a heat wave \\
\hline CWDI & Cold Wave Duration Index & Length of a cold spell \\
\hline FD & Days below freezing & Frost days \\
\hline
\end{tabular}

For a complete list and formal definitions, see http://etccdi.pacificclimate.org/list_27_indices.shtml temperature extremes (Sect. 5), and various open questions (summary section). Different readers may be interested in different surveys. Accordingly, the sections are autonomous allowing a reader to skip to a particular section(s) of interest.

\section{Extreme statistics and associated large scale meteorological patterns (LSMPs)}

\subsection{Definitions of extreme events}

The expert team on climate change detection and indices (ETCCDI) under the auspices of the World Meteorological Organization's CLIVAR program provide a useful, but somewhat incomplete starting point to explore the relationship between extreme temperatures and LSMPs. The ETCCDI indices as well as software to calculate them are available at http://etccdi.pacificclimate.org and are described in Alexander et al. (2006). The ETCCDI temperature indices are summarized in Table 1 and are designed for detecting and attributing human effects on extreme weather and do not necessarily represent particularly rare events. However, extreme value statistical methodologies can be applied to quantify the behavior of the tails of the distribution of certain ETCCDI indices and reveal insight into truly rare events (Brown et al. 2008; Peterson et al. 2013). Another common statistical measure is the return value (or level). Under a changing climate, the return value can be interpreted as an extreme quantile of the temperature distribution that varies over time (e.g., the 20-year return value may be interpreted as that value that has a $5 \%$ chance of being exceeded in a particular year). Trends in these measures of extreme temperature are detectible at the global scale (Brown et al. 2008) and have been attributed to human emissions of greenhouse gases (Christidis et al. 2005). At local scales, increases and decreases are observed reflecting the significant amount of natural variability in extreme temperatures.

Figure 1 shows observed trends over North America from 1950 to 2007 in 20-year return values of the hottest/ coldest days and hottest/coldest nights. The temperature of very cold nights (Fig. 1d) exhibits pronounced warming over the entire continent as does the temperature of very cold days (Fig. 1b). The pattern of changes in the temperature of very hot days (Fig. 1a) and very hot nights (Fig. 1c) follows that of average temperature change with strong cooling in the southeastern United States. This "warming hole" has been linked to sea surface temperature patterns in the equatorial Pacific (Meehl et al. 2007) and changes in anthropogenic aerosols in the eastern US (Leibensperger et al. 2012). Changes are more pronounced at the higher latitudes, except in Quebec and Newfoundland. This analysis extends the work of Peterson et al. (2013) and uses annual anomalies to define the extreme indices. Although illustrative of the statistical techniques, analyses of annualized measures of extreme temperature cannot identify associated LSMPs that develop and dissipate on a much shorter time scale. Furthermore, events of high and low impact are better separated in seasonal analyses. 
(a)

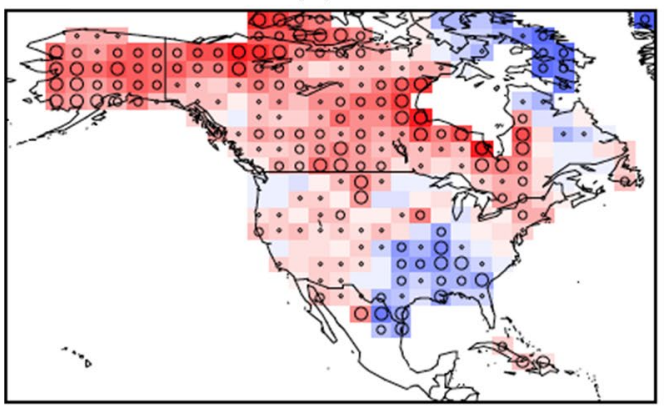

(b)

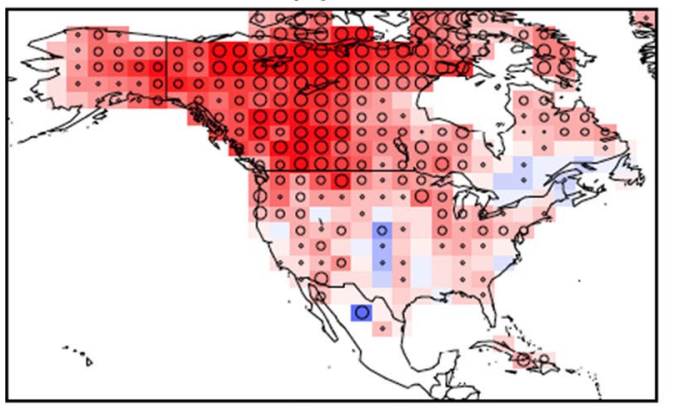

Fig. 1 Change over 1950-2007 in estimated 20-year annual return values $\left({ }^{\circ} \mathrm{C}\right)$ for a hot tail of daily maximum temperature (TXx), b cold tail of daily maximum temperature (TXn) $\mathbf{c}$ hot tail of daily minimum temperature ( $\mathrm{TNx}$ ) and $\mathbf{d}$ cold tail of daily minimum temperature (TNn). Results are based on fitting extreme value statistical models with a linear trend in the location parameter to exceedances of a location-specific threshold (greater than the 99th percentile for upper tail and less than the 1th percentile for lower tail). As this

\subsection{Application of extreme value statistical techniques}

The observed changes in Fig. 1 are calculated using a time-dependent point process approach to fit "peaks over threshold" statistical models (Coles 2001). In this case, the extension of stationary extreme value methods to a timedependent formalism used time as a "covariate" quantity to the ETCCDI indices (Kharin et al. 2013). A principal advantage of a fully time dependent formalism over a quasi-stationary approximation (Wehner 2004) is that the amount of data used to calculate extreme value parameters is substantially increased, resulting in higher quality fitted distributions and hence more accurate estimates of long period return values. Calculations involving climate model output gain additional statistical accuracy by using multiple realizations from ensembles of simulations, provided they are independent and identically distributed.

The "block maxima" and "peaks over threshold" methods to fit the tails of the distributions of random variables are asymptotic formalisms (Coles 2001). In this terminology, "block maxima" refers to use of only the maximum value during each "block" of time, usually a single season or year. The resulting generalized extreme value (GEV) or (c)

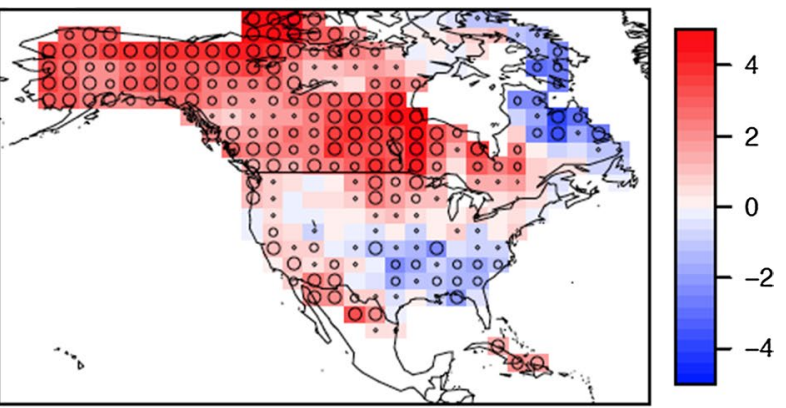

(d)

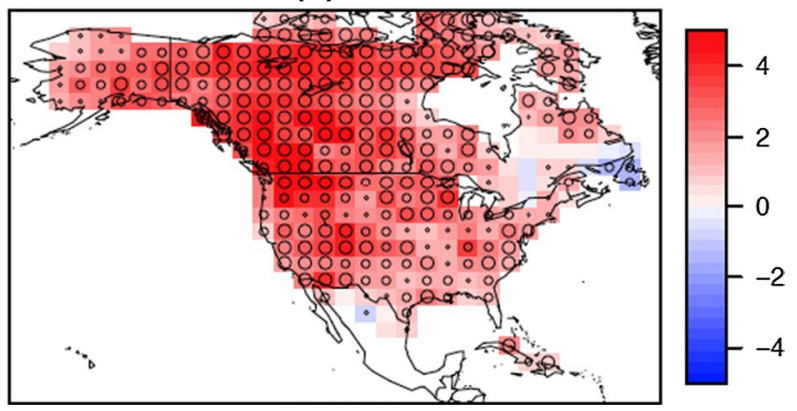

analysis was based on anomalies with respect to average values for that time of year, hot minimum temperature values, for example, are just as likely to occur in winter as in summer. The circles indicate the $\mathrm{z}$-score for the estimated change (estimate divided by its standard error), with absolute $\mathrm{z}$-scores exceeding 1,2, and 3 indicated by open circles of increasing size. Higher z-score indicates greater statistical significance

Poisson and generalized Pareto distributions (GPDs) are both three parameter functions and can be transformed between each other. Hence provided that the data used to fit a distribution are in the "asymptotic regime", i.e. far out in the tail of the distribution, the two methods are equivalent. Uncertainty in the estimate of long period temperature return values resulting from limited sample size can be appreciable and may be as large as that from unforced internal variability (Wehner 2010). However, variations in these estimates from multi-model datasets such as CMIP3/5 are generally significantly larger.

Confidence in the estimates of the statistical properties of the tail of the parent distribution of a random variable can be ascertained by exploring the sensitivity to the sample size used to fit the extreme value distribution. For block maxima methods, the length of the block is a season (or effectively so for temperature if the block length is a year). Lengthening the block makes the sample size smaller; shortening it makes the sample size larger since only one extreme value is drawn from each block. Such sensitivities are somewhat more straightforward to explore with peaks over threshold (POT) methods. Typical thresholds may be chosen between 80 and $99 \%$ depending on 
the size of the parent distribution that the extreme values are drawn from. However, standard POT methods may not discriminate between extreme values that occur at successive dates when the individual extreme values may not be truly independent. In these cases, declustering techniques (Coles 2001) are applied to avoid biased (low) estimates of the uncertainty. The trends in extreme temperature shown in Fig. 1 are calculated using such a declustering technique and a POT formalism with time as a linear covariate. An alternative approach retains possibly dependent consecutive extremes, adjusting the estimates of uncertainty through either resampling or more advanced techniques for quantifying extremal dependence (e.g., Fawcett and Walshaw 2012). Furthermore, LSMPs responsible for extreme events can be formed using only the dates of the onset of the event (e.g. Grotjahn and Faure 2008; Bumbaco et al. 2013) reducing the risk of autocorrelated extremes. In the cited studies, a 5 day gap was typically required between events. Low frequency factors (or climate modes), such as ENSO, are best treated using the previously mentioned covariate techniques.

Some of the advantages and challenges of applying statistical methods based on extreme value theory to analyze non-stationary climate extremes have been pointed out previously (e.g., Katz 2010), but are still not necessarily well appreciated by the climate science community. Conventional approaches tend to be either: (1) less informative (e.g., analyzing only the frequency of exceeding a high threshold, not the excess over the threshold and not measuring the intensity of the event); or (2) less realistic (e.g., based on assumed distributions such as the normal that may fit the overall data well, but not necessarily the tails). When relating extremes to LSMPs, standard regression approaches would not quantify the uncertainty in the relationship as realistically as using extremal distributions with covariates. Challenges in extreme value methods include specifying the dependence on LSMPs of the parameters of the extremal distributions in a manner consistent with our dynamical understanding. Moreover, heat waves and CAOs are relatively complex forms of extreme events, some of whose characteristics can be challenging to incorporate into the framework of extreme value statistics (Furrer et al. 2010). Finally, another advantage of the POT approach over the block maxima approach is being able to incorporate daily indices of LSMPs as covariates (not just monthly or seasonally aggregated indices).

\subsection{Identification of LSMPs related to extreme temperatures}

Several methods have been used to identify LSMPs that occur in association with extreme temperature events. These methods and their properties are summarized in
Table 2. The text summarizes each method, its advantages and its disadvantages.

\subsubsection{Composites}

Composite methods define the LSMP using a target ensemble average. The values at a grid point for a field on specified 'target' dates are averaged together. These dates might be when a temperature event begins (onset dates) defined as when some parameter(s) first meet some threshold and duration criteria. Table 3 illustrates various threshold and duration criteria that have been used to identify short-term extremely hot events. The different definitions yield somewhat different dates and results. A definition using a physiological hazard (Robinson 2001) might not be satisfied at night in the coastal and some inland regions of the West, even though the daytime temperature threshold is well exceeded. Lower thresholds (90th percentile) generate more events thus increasing the sample size that can improve the statistical fit, though the behavior of the highest $1 \%$ may not be well fit. Similarly, the number of stations (or the size of the area over which those stations occur) impacts which dates are identified, even for regions that would seem to be meteorologically consistent; for example, which stations and how many are included from the Central Valley of California changes which dates exceed a threshold. Also, different definitions target different purposes: Grotjahn and Faure were interested in the LSMPs at the onset of the hottest events while Meehl and Tebaldi were interested in finding the longest duration events of some importance. The number of dates averaged equals the number of ensemble members.

Compositing has several advantages. One can track LSMP formation by compositing fields with respect to the onset time of each event. Meteorologically relevant full fields (or anomalies) are obtained and composite analyses are constructed to obtain information on the synoptic and dynamical time evolution. The method is non-parametric in that it does not make any assumption about the pattern or the event statistics. Unlike some other methods, criteria can be applied (typically a minimum waiting period between events) to ensure events are independent. Significance can be assessed using a bootstrap resampling procedure where the target ensemble value at a grid point is compared to the distribution of values at that grid point found from a large number of 'random ensembles' (each of which uses the same number but randomly-chosen dates). Values above (or below) a threshold of the random ensemble distribution imply significantly high (low) values at that grid point. For example, a target ensemble value equal or higher than the top 10 of 1000 random ensemble values at that point is significant at approximately the $99 \%$ level. Figure 2 shows the LSMPs for California Central Valley cold air outbreaks 


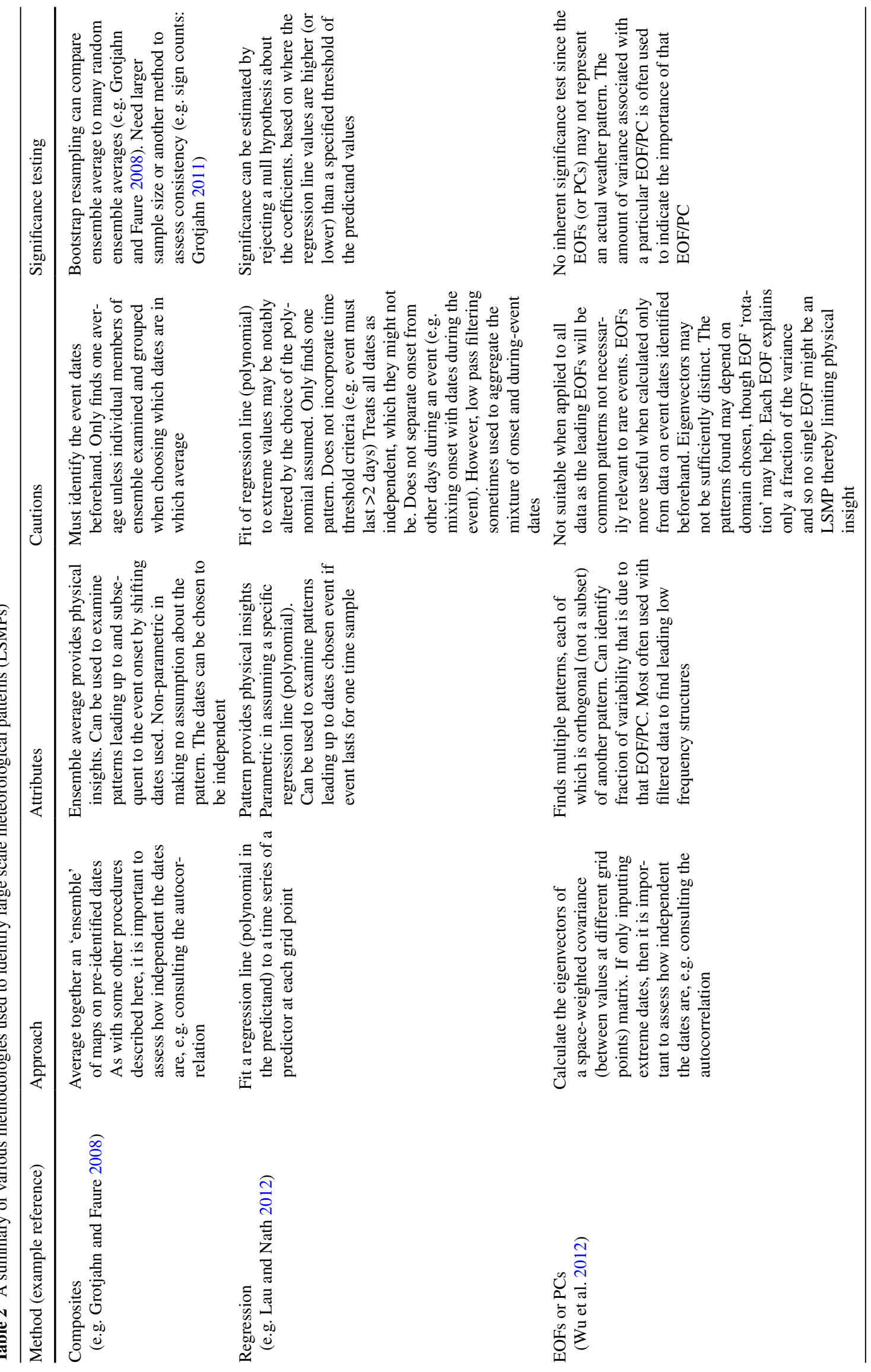




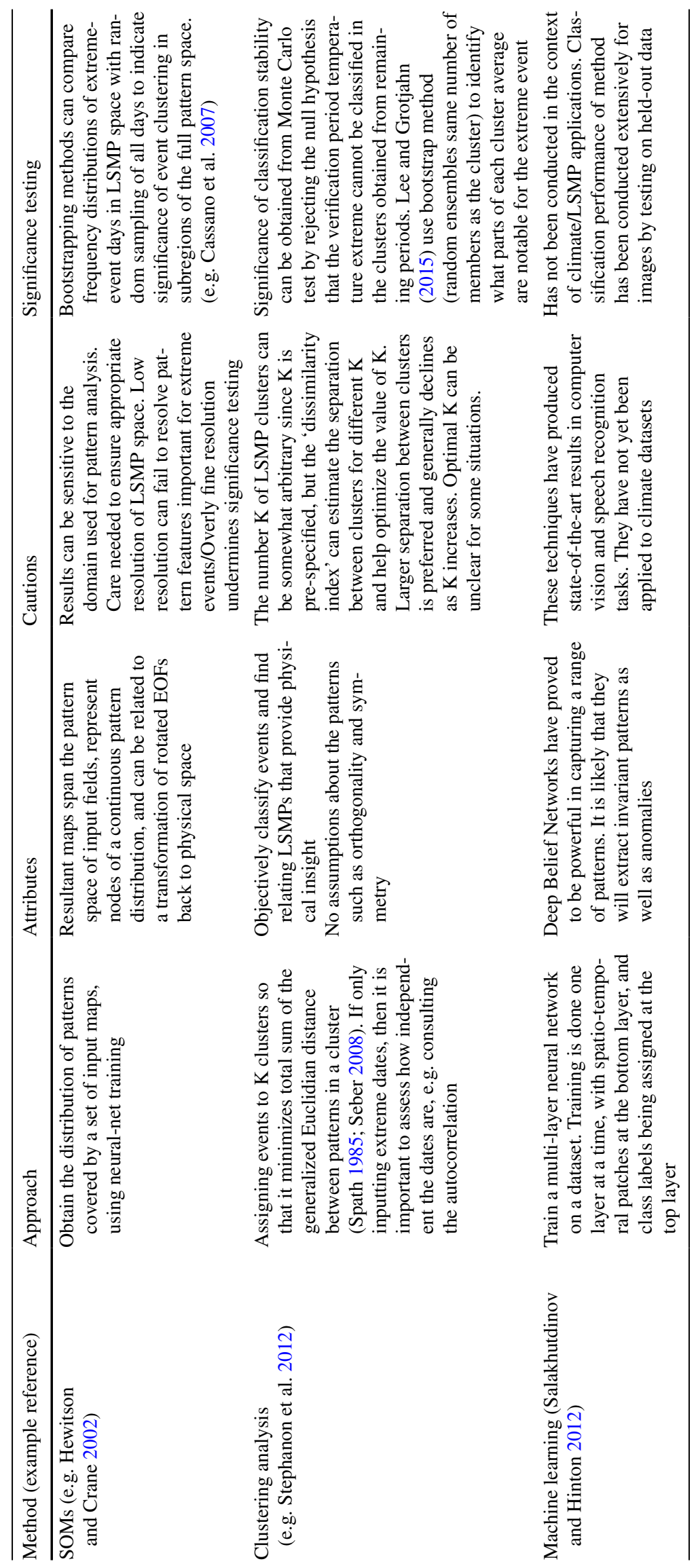


Table 3 Sampling of Various Criteria Used in Heat Wave and Hottest Day Definitions

\begin{tabular}{|c|c|}
\hline Source & Definition \\
\hline Robinson (2001) & $\begin{array}{l}\text { A period of at least } 48 \mathrm{~h} \text { during which neither the overnight low nor the } \\
\text { daytime heat index Hi falls below the NWS heat stress thresholds }(80 \text { and } \\
\left.105{ }^{\circ} \mathrm{F}\right) \text {. At stations where more than } 1 \% \text { of both the high and low Hi } \\
\text { observations exceed these thresholds, the } 1 \% \text { values are used as the heat } \\
\text { wave thresholds }\end{array}$ \\
\hline Hajat et al. (2002) & $\begin{array}{l}\text { 3-day moving average temperatures }>\text { the } 99 \text { th percentile of the whole record } \\
\text { of temperature }\end{array}$ \\
\hline Meehl and Tebaldi (2004) & $\begin{array}{l}\text { The longest period of consecutive days satisfying the following } 3 \text { conditions } \\
\text { 1. Daily maximum temperature }>\mathrm{T} 1 \text { for at least } 3 \text { days } \\
\text { 2. Average daily maximum temperature }>\mathrm{T} 1 \text { for entire period } \\
\text { 3. Daily maximum temperature }>\mathrm{T} 2 \text { for every day of entire period, } \\
\text { where } \\
\mathrm{T} 1 \text { (threshold } 1)=97.5 \text { th percentile of distribution of maximum temperatures } \\
\text { in the observations and in simulated present day climate } \\
\mathrm{T} 2=81 \text { st percentile }\end{array}$ \\
\hline Beniston (2004) & $\begin{array}{l}\text { Maximum T exceeding the 90th quantile of summer temperature }\left(30^{\circ} \mathrm{C}\right) \text { at a } \\
\text { station (Basil, Switzerland) }\end{array}$ \\
\hline Lipton et al. (2005) & $\begin{array}{l}\text { Daily maximum high temperature remains } 2 \text { standard deviations above normal } \\
\text { for at least } 2 \text { consecutive days }\end{array}$ \\
\hline Gosling et al. (2007) & $\begin{array}{l}\text { For } 3 \text { or more days the maximum } T \text { must be } \geq 95 \text { th percentile of the maxi- } \\
\text { mum } \mathrm{T} \text { in the summer climatology }\end{array}$ \\
\hline Grotjahn and Faure (2008) & $\begin{array}{l}\text { At least } 3 \text { consecutive days during which the daily maximum temperatures are } \\
\text { above } 100^{\circ} \mathrm{F}\left(38^{\circ} \mathrm{C}\right) \text {, and with at least one above } 105^{\circ} \mathrm{F}\left(40.5^{\circ} \mathrm{C}\right)\end{array}$ \\
\hline Bachmann (2008) & $\begin{array}{l}\text { Two combinations of criteria, I and II, were tested } \\
\text { I. Must satisfy both conditions (where anomaly is relative to long term daily } \\
\text { mean): } \\
\text { 1. At least } 3 \text { consecutive days with daily anomaly maximum temperature } \\
\geq 10^{\circ} \mathrm{C} \\
\text { 2. At least } 1 \text { day must have maximum temperature anomaly } \geq 15^{\circ} \mathrm{C} \\
\text { II. Must satisfy the } 2 \text { conditions above plus this additional condition: } \\
\text { 3. The average maximum temperature for the event } \geq 100 \mathrm{~F}\left(38^{\circ} \mathrm{C}\right)\end{array}$ \\
\hline Gershunov et al. (2009) & $\begin{array}{l}\text { Individual stations exceeding the 99th percentile for } 1,2 \text {, or } 3 \text { dates in a } \\
\text { row are aggregated, with the highest aggregation of values over the region } \\
\text { including all of California and Nevada determining a ranking for an event. } \\
\text { Daytime maximum and nighttime (highest) minimum treated separately }\end{array}$ \\
\hline Lyon (2009) & $\begin{array}{l}\text { Daily maximum temperature must exceed the 90th percentile for at least } \\
3 \text { consecutive days, where the percentile is based daily values from the } \\
\text { 3-month summer season. Also tested, same temperature criterion over } 5 \\
\text { consecutive days }\end{array}$ \\
\hline Grotjahn (2011) & $\begin{array}{l}\text { Daily maximum temperature anomaly (relative to long term daily mean) nor- } \\
\text { malized by daily long term mean standard deviation at all three CV stations } \\
\text { (KRBL, KFAT, KBFL) must all exceed } 1.6 \text { Note: this defines hottest days, } \\
\text { not heat waves }\end{array}$ \\
\hline Bumbaco et al. (2013) & $\begin{array}{l}\text { Daily maximum temperature anomalies for stations in a region are averaged } \\
\text { together. Heat wave when regional average daily anomaly exceeds 99th } \\
\text { percentile for } 3 \text { or more consecutive days }\end{array}$ \\
\hline
\end{tabular}

and heat waves obtained by this method, including bootstrap resampling significance.

Compositing has some disadvantages that can be addressed. The identification of the extreme event dates must be done separately and before the compositing. The composite produces one target ensemble average (for a specific field and level) for each set of target dates. If more than one LSMP can produce the extreme event, then that must be identified either with one or more additional criteria when choosing dates or identified by examining (perhaps qualitatively) the maps for each individual member of the target ensemble. A procedure like adding the number of positive and subtracting the number of negative anomaly values at a grid point in the target ensemble members (called the 'sign count' in Grotjahn 2011) can assist with identifying multiple patterns. (If the sign count equals the number of ensemble members, then all members have the same sign of the anomaly field at that location.) Lee and Grotjahn (2015) apply a cluster analysis to distinctly different parts of LSMPs 

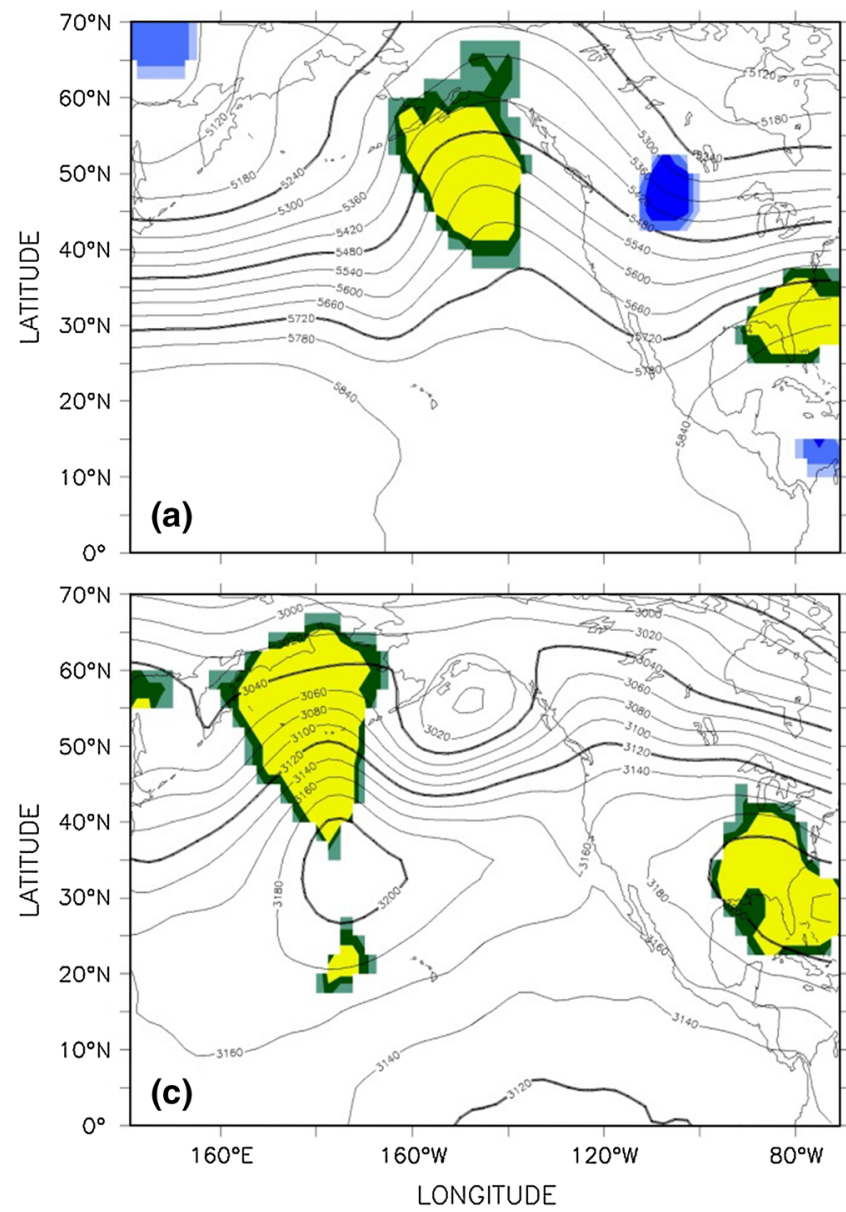

Fig. 2 Example large scale meteorological patterns (LSMPs) obtained as target ensemble mean composites for two types of California Central valley extreme events. Cold air outbreaks in winter (DJF) at $\mathbf{a} 72 \mathrm{~h}$ prior and $\mathbf{b}$ at onset of the events are shown in the $500 \mathrm{hPa}$ geopotential height field. Heat waves during summer (JJAS),

prior to California heat waves and identify two ways the onset LSMPs form.

\subsubsection{Regression}

Regression estimates one quantity (the predictand) using a function of one or more other quantities (the predictors). The method is often parametric in assuming a specific function relates a predictor to the predictand (but nonparametric methods exist, too). An example predictor might be daily minimum surface temperature and the predictand might be $700 \mathrm{hPa}$ level meridional wind. At each grid point the value of the predictand can be estimated using a polynomial function of the predictor, where the coefficients of that polynomial are calculated to minimize a squared difference between actual predictand values and polynomial values at that grid point. In general, the coefficients differ from grid point to grid point. To find the LSMP in this example of

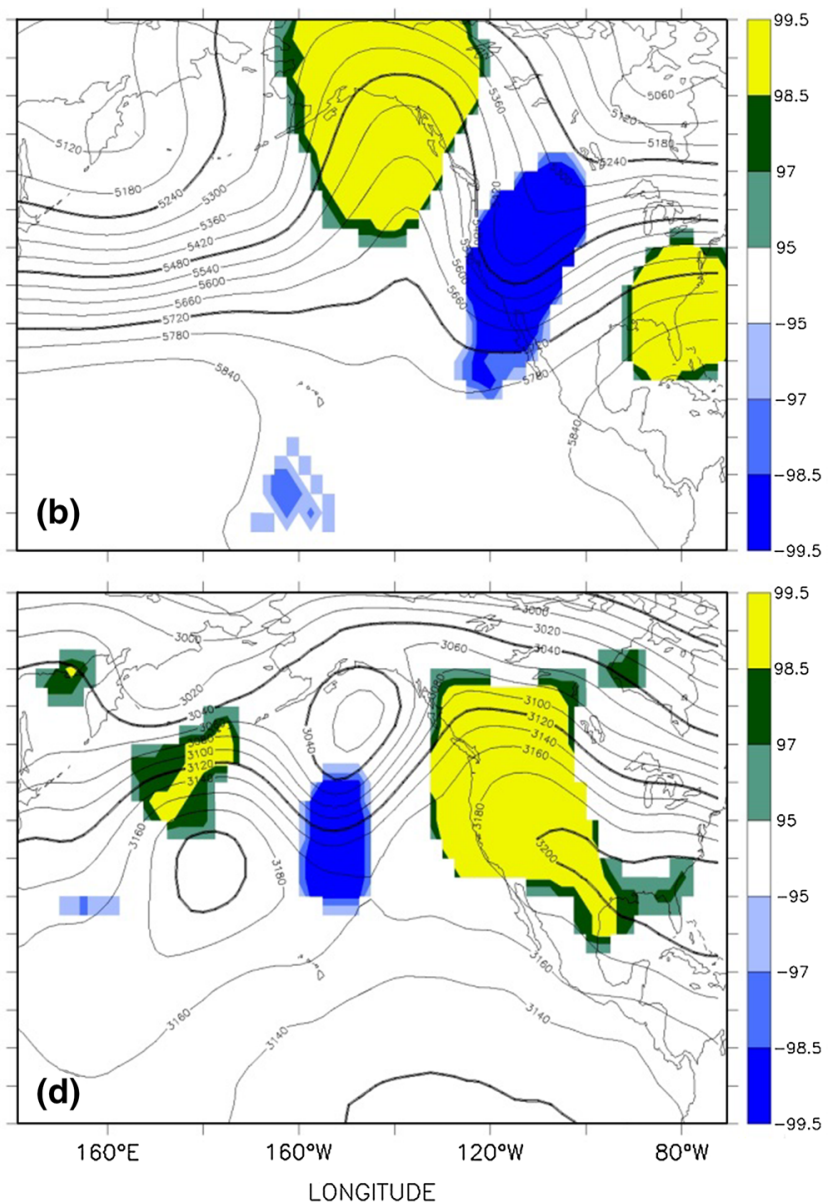

c $36 \mathrm{~h}$ prior and $\mathbf{d}$ at the onset are shown in the $700 \mathrm{hPa}$ geopotential height field. Shading indicates significance at the highest or lowest $5 \%$ level, with the innermost shading significant at the $1.5 \%$ level. Further discussion is in Grotjahn and Faure (2008)

extreme cold events, the polynomial can be used to construct the predictand at each grid point using a predictor value such as two standard deviations below normal.

The pattern obtained by regression can provide physical insights by directly linking the patterns in the predictand to extremes in the predictor. For example, lower tropospheric $(700 \mathrm{hPa})$ winds prior to a California CAO flow from northern Alaska and northern western Canada to reach California without crossing over the Pacific Ocean. Regression can be used to examine patterns leading up to (or after) event onset dates by offsetting in time the predictor values from the predictand values when calculating the regression coefficients. The LSMP is again the resultant predictand when the predictor is at some specified value (e.g. predictor equals two standard deviations below normal). Significance can be estimated by rejecting a null hypothesis (e.g. that the regression coefficient is zero at the $1 \%$ level using a student's $t$ test). 
One disadvantage of regression is that the assumption of a specific polynomial to represent how the predictand varies relative to the predictor. The fit of the regression line (polynomial) to extreme values may be notably altered by the order of the polynomial assumed. Regression, like composites, only finds one pattern. Regression does not incorporate event duration criteria (such as: the event must last at least 3 days). Regression treats all dates as independent, which they are not likely to be; however this can be somewhat mitigated by sub-sampling the data (e.g. only use every fifth day). Subsampling might be combined with low pass filtering to aggregate the mixture of onset and duringevent dates. Another disadvantage is that a portion of the pattern may be highly significant but only have small correlation to the predictor.

\subsubsection{Empirical orthogonal functions}

Empirical orthogonal functions (EOFs) or principal components (PCs) can be used to identify LSMPs for extreme events. EOFs are the eigenfunctions of a matrix formed from the covariance between grid points on maps. EOFs from all maps in a time record will be ordered based on the eigenfunctions responsible for the largest amount of variance between time samples. Such eigenfunctions are the most common modes of variability and so not likely to be LSMPs of extreme events that are rare (except as mentioned in the introduction). However, EOFs can be formed only from maps selected in reference to an extreme event, such as maps only on the target dates of events onset. (EOFs of common low frequency modes may influence short-term extreme events focused on in this paper, as discussed in Sect. 3.1.) Weighting can be used for a variable grid spacing (such as occurs when using equal intervals of longitude across a range of latitudes).

An advantage of EOFs/PCs is the method finds multiple patterns, each of which is orthogonal (not a subset) of another pattern. The method can calculate the fraction of variability that is due to each EOF/PC. This approach is most often used with filtered data to find low frequency structures. This method is suitable for finding patterns leading up to and after the event by shifting the dates chosen by the event criteria (and only using those dates). In a study of California Central Valley hot spells, Grotjahn (2011) found the leading EOF based on dates satisfying the criteria in Table 3 to be very similar to the corresponding ensemble mean composite.

A disadvantage is that the patterns found may depend on the domain chosen, though EOF 'rotation' may help. Also, each EOF may explain only a small fraction of the variance and no single EOF might be an LSMP thereby limiting physical insight. Different leading EOFs/PCs might have structures influenced by the required orthogonality and possibly not a pattern that occurs during an event. While the amount of variance associated with a given EOF is used to indicate the importance of the EOF, there is no inherent statistical significance test. Hence it can be unclear what portions of the EOF are significantly associated with the extreme event and what parts are not (and happen to reflect limited variation in the finite sample).

\subsubsection{Clustering analysis}

Clustering analysis is terminology indicating a widely used partitioning procedure that identifies separate groups of objects having common structural elements. Clustering analysis has been used to classify distinct sets of LSMPs associated with extreme events (Park et al. 2011; Stephanon et al. 2012). When we have 100 historical hot spell events over a given region, not all extreme events may have the same LSMP on or prior to their onset. Some events may have a wave-like height field, others may have a dipole pattern, and still others may have a third pattern. Although detailed grouping procedures vary for every clustering technique, the basic concept is to minimize the overall distance between patterns among events in resultant groups. For example, the k-means clustering technique applies an iterative algorithm in which events are moved from one group to another until there is no additional improvement in minimizing the squared Euclidean point-to-centroid distance in a group (Spath 1985; Seber 2008), where each centroid is the mean of the patterns in its cluster.

Output of clustering analysis is just the average field of events in each cluster, similar to the output from composite analysis. Unlike composite analysis in which members of clusters are pre-identified, the essential point of clustering analysis is to objectively classify events based on spatial pattern similarity. By applying cluster analysis to group similar onset patterns, one can isolate distinct dynamical origins of different extreme temperature events. Another advantage is that resultant clusters are based on physical maps without assumptions of orthogonality and symmetry such as in the mode separation by EOF/REOF. The robustness of a hot spell classification can be tested by a Monte Carlo test as follows. First one calculates a stability score that is the ratio of the number of verification period heat waves that are correctly attributed over the total number heat waves in the cluster. Second one estimates the probability density function (PDeF) of the null hypothesis that cluster assignment is purely random. Significance of each cluster can be estimated by rejecting a null hypothesis (e.g. stability score is located within highest $99 \%$ of PDeF).

A disadvantage of clustering analysis is that one prespecifies the number of clusters (e.g. $\mathrm{k}$ in k-means clustering). Determining the number $\mathrm{k}$ is subjective if one does not have sufficient prior knowledge of related physical 


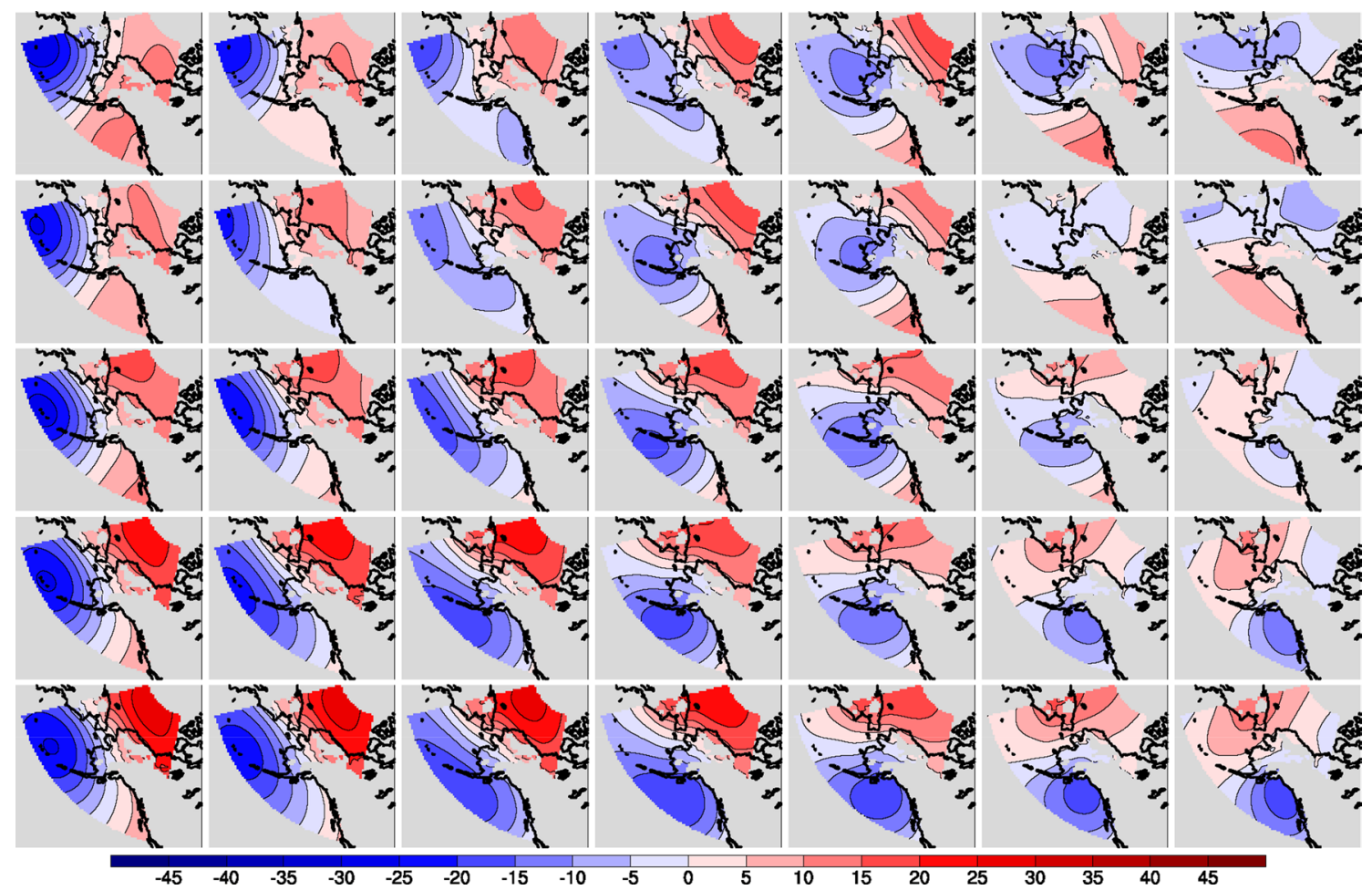

Fig. 3 Self-organizing map of synoptic weather patterns in a region focused on Alaska. The SOM array maps give the departure (in $\mathrm{hPa}$ ) of sea level pressure (SLP) from the domain averaged sea level pressure. The SOM used daily December-January-February (DJF) SLP for 1997-2007 from ERA-interim reanalyses and output from a regional climate model. Locations with elevation exceeding $500 \mathrm{~m}$ are not included in the maps to avoid using SLP in regions strongly influenced by methods used to extrapolate SLP from surface pressure patterns. There are several statistics to check the optimal number of $\mathrm{k}$ such as 'distance of dissimilarity' (Stephanon et al. 2012). Another disadvantage is the ambiguity of cluster assignment for certain events. Another disadvantage is the patterns of such events cannot be assigned clearly to one group over another group. Part of a pattern may resemble Cluster \#1, while another part may be more similar to Cluster \#2. To avoid ascribing some marginal events to specific clusters, probabilistic clustering methods (e.g. Smyth et al. 1999) are developed, which suggests the possibility (e.g. percentage) that an event could be assigned to each cluster rather than assigning it only to one cluster. If one increases the cluster number, one can expect to decrease such ambiguity in classification. However, the point of clustering analysis is to give a physical insight with minimal groups and not to interpret every single episode.

\subsubsection{Self-organizing maps}

Self-organizing maps (SOMs; Kohonen 1995) are twodimensional arrays of maps that display characteristic behavior patterns of a field (e.g., Cavazos 2000; Hewitson and Crane 2006; Gutowski et al. 2004; Cassano et al. 2007). The SOM array is a discretization of the continuous pattern space occupied by the field examined. Thus, in contrast to clustering analysis, SOMs do not assume a clumping together of patterns, though such behavior can emerge if present in the input data. Figure 3 gives an example of a SOM array of synoptic weather patterns in sea level pressure over a region centered on Alaska. Individual maps in the array represent nodes in a projection of this continuous space onto a two-dimensional surface, with the size of the array determined by the degree of spatial discretization of the SOM space one "feels" is needed for the analysis at hand. The two dimensions show the two primary pattern transitions for the field examined. Although one could, in principle, use more than two dimensions, typical practice in climatological work has used only two.

The input maps themselves determine the degree and types of pattern transitions, hence the "self-organizing" nature of the resulting array. The SOM node array is trained on a sequence of input maps through an artificial neural net technique. The SOM array does not necessarily favor the largest scales in the input data, but rather the scales most relevant to the field for the domain and resolution examined. Consequently, SOMs can extract nonlinear pattern changes in fields, such as shifts in strong gradients. In addition, the pattern at each node is essentially 
a composite of input maps with similar spatial distribution for the field examined, so that patterns in the SOM array show archetypal patterns of the field examined and directly lend themselves to physical interpretation. Typically, the SOM array displays features having the highest temporal variance in the input data. From this perspective, the SOM array is roughly akin to a transformation of a rotated EOF from spectral space back to physical space.

An advantage of SOMs is that one can identify the nodes where extreme events occur frequently and thus the physical behavior yielding extremes. For example, extreme events may tend to cluster in a small portion of SOM space, thereby allowing identification of LSMPs yielding extreme events. A further advantage is that if more than one group emerges in the SOM-space frequency distribution, then the grouping provides a SOM-determined segregation of different types of extreme events. One can then focus analysis and composites of additional fields (e.g., precipitation, winds, temperature) on only events of the same type. For example, Cassano et al. (2006) used SOMs of sea-level pressure patterns over Alaska to determine which synoptic weather patterns were responsible for extreme wind and temperature events at Barrow, Alaska. They then found robust links between these large-scale synoptic weather patterns and local weather features (precipitation, winds, and temperature). One can construct estimates of the significance of differences in frequency distributions in SOM space through bootstrapping procedures to estimate the likelihood that frequency distributions are not simply the result of random, finite sampling of the pattern space. Thus one can compare frequency distributions between a present and projected climate to assess potential climate changes in LSMPs, or between observational and model climates to assess similarity of observed and simulated LSMPs yielding extremes.

A disadvantage of SOMs is that the array size is predetermined by the user, and there is no clear, objective guideline for selecting array size. There are, however, some factors that can affect the array-size choice. The issue of significance limits the degree of discretization (number of nodes) one applies to the SOM space. Fine discretization will allow apparent detection of small differences in how different data sets occupy pattern space, but fine discretization will also render very noisy frequency distribution functions of the fields in SOM space, thus undermining detection of any significant differences. Coarse discretization limits the ability of the SOM procedure to resolve features producing the extreme events, so a further disadvantage is that an insufficient array size may obscure grouping that may be present in the data. The training method also requires specification of parameters that govern the training process. A well-trained SOM is insensitive to these choices, but care is needed to ensure such a result. In addition, like some of the other methods described here, the extreme events are defined separately from the SOM analysis.

\subsubsection{Machine learning and other advanced techniques}

Looking to the future, we note that substantial progress has been made in the field of machine learning for extracting patterns from Big Data. Commercial organizations such as Google and Facebook rely on sophisticated, scalable analytics techniques for mining web-scale datasets. Both supervised and unsupervised machine learning tools could play an important role in extracting spatio-temporal patterns from climate datasets. The technique Deep Belief Networks (Salakhutdinov and Hinton 2012) has been applied with tremendous success to classifying objects in digital images (Krizhevsky et al. 2012) and speech recognition (Hinton et al. 2012). These methods have substantially outperformed existing techniques in the field with the same underlying learning algorithm. While these techniques have not yet been adapted for a multivariate spatio-temporal dataset (such as in climate), research efforts are currently underway to evaluate the performance of such methods in extracting patterns as well as anomalies from datasets. It is too early to discern pros and cons fully for such methods.

\subsection{Including large scale patterns in extreme statistics}

Application of covariates in extreme value methods (termed "conditional extreme value analysis") is relatively new to the climate science community, although it has been available to the larger statistics community for some time (Coles 2001). The basic idea of conditional extreme value analysis is to allow the extremal distribution to be dynamic; that is, shifting depending on the observed value of an index of a climate mode or LSMP (the index would be an example of a "covariate"). The book by Coles includes an example in which annual maximum sea level is related to a climate mode, the Southern Oscillation. In their study of changes in extreme daily temperatures, Brown et al. (2008) used the $\mathrm{NAO}$ as a covariate in addition to a trend component.

Such techniques have proven useful in connecting extreme temperatures to LSMPs. Sillmann and CrociMaspoli (2009) and Sillmann et al. (2011) used a blocking index as a covariate for extremely cold European winter temperatures and found that extreme value distributions (based on block minima) were better fit and long period return values were somewhat colder. Furthermore, they concluded that projected future extremely cold events in Europe were less influenced by atmospheric blocking because of projected shifts in North Atlantic blocking patterns. Photiadou et al. (2014) used a similar technique (but based on the POT approach rather than block maxima) to connect blocking and other indices to European 
high temperature events finding that while El Nino/Southern Oscillation (ENSO) does not exert much influence on extremely high temperature magnitudes or duration, the North Atlantic Oscillation (NAO) and atmospheric blocking do. However to date, such covariate techniques relating atmospheric blocking to extreme temperatures have not been applied to North America. Many physically based covariate quantities potentially offer insight into the mechanisms behind extreme temperature events and the response to changes in the average climate. Good North American candidates for covariates include indices measuring modes of natural variability such as those describing the ENSO, the Pacific Decadal Oscillation (PDO), the NAO, the North Atlantic Subtropical High (NASH), and various blocking indices.

The ETCCDI indices were designed for climate change detection and attribution purposes rather than for exploring the mechanisms causing extreme events. They are not ideal for connecting extreme temperature events to LSMPs and they are not descriptive of particularly rare events. However, ETCCDI indices are designed to be robust over the observational record and have been calculated and described for CMIP5 models by Sillmann et al. (2013a) (see Table 1). ETCCDI indices are intended to be applied globally and be meaningful in areas of sparse observations. The relatively dense network of North American observations since the beginning of the twentieth century permits the construction of more specialized LSMP extreme indices linked to specific extreme events. Grotjahn (2011) defines an index that is an unnormalized projection of key parts of a target ensemble LSMP onto a daily map of the corresponding variable. (He combined such projections onto $850 \mathrm{hPa}$ temperature and $700 \mathrm{hPa}$ meridional wind to form his 'circulation index'.) His target ensemble members are from dates satisfying criteria listed in Table 3 . The key parts of the fields used are those where all the extreme events in the training period were consistent, at least in having the same anomaly sign. Grotjahn (2011) found that extreme values of such an index (based on upper air data) occurred on many of the same dates as extreme values of surface stations in the California Central Valley (CCV). Statistically significant relationships exist between extreme values of this circulation index and both the rate of CCV daily maximum temperature exceeding a high threshold and the distribution of the excess over the threshold (Katz and Grotjahn 2014). Grotjahn (2013) used such an index to show that a particular climate model was notably under-predicting the occurrence frequency (by half) of CCV hot spells. Grotjahn (2015) used such an index to show how that same model compared with a 55 year historical record and what the model implied for CCV hot spells during the last half of the twentyfirst century under two representative concentration pathways (RCPs) of greenhouse gases.

\section{Large scale meteorological patterns related to extreme temperature events}

Intraseasonal extreme temperature events (ETEs) are almost always associated with regional air mass excursions induced by circulation anomalies that are part of large-scale meteorological patterns (LSMPs). LSMPs can include synoptic features (e.g., midlatitude cyclones; Konrad 1996) that enhance the ETE and often with scales similar to a teleconnection pattern (though the nodes may not align and ETE onset, itself, may impact the teleconnection pattern, Cellitti et al. 2006). In some cases, the LSMP is interpreted as a juxtaposition of teleconnection patterns that leads to ETE events (Lim and Kim 2013). Heuristically, the role of LSMPs in producing ETEs could be considered the result of either (1) a direct contribution to the large-scale circulation that facilitates the air mass excursion or (2) the indirect modulation of sub-scale variability, such as regional modulation of storm track behavior by blocking patterns. Besides such dynamically driven impacts, there exist possible local impacts related to the interaction of the LSMP with local topography or coastline features, leading to possible local symmetries in the response pattern (e.g., Loikith and Broccoli 2012). Current knowledge of the remote forcing, dynamics and local forcing of LSMPs associated with ETEs is summarized next.

\subsection{Remote forcing of LSMPs and ETEs}

\subsubsection{Connection to low frequency modes of climate variability}

Numerous observational studies have ascertained that ETE behavior is modulated by recurring large scale teleconnection patterns, particularly during winter. On intraseasonal time scales there is a substantial modulation of North American ETEs during winter by the Pacific-North American (PNA) pattern, North Atlantic (or Arctic) Oscillation (NAO or AO) and blocking patterns (Walsh et al. 2001; Cellitti et al. 2006; Guirguis et al. 2011). On interannual and longer time scales additional climate modes such as El Nino-Southern Oscillation (ENSO) and the Pacific Decadal Oscillation (PDO) are also implicated (Westby et al. 2013). General relationships that have emerged from these statistical analyses are illustrated in Fig. 4: The positive (negative) phase of the NAO favors the occurrence of warm (cold) events over the eastern (southeastern) United States. The positive (negative) phase of the PNA tends to favor cold events over the southeastern (northwestern) US. These connections to climate modes are neither unique nor independent. For example, the regional influence of the PNA pattern on ETEs largely mirrors that of both the PDO and ENSO (Fig. 4) since the midlatitude atmospheric signatures of 

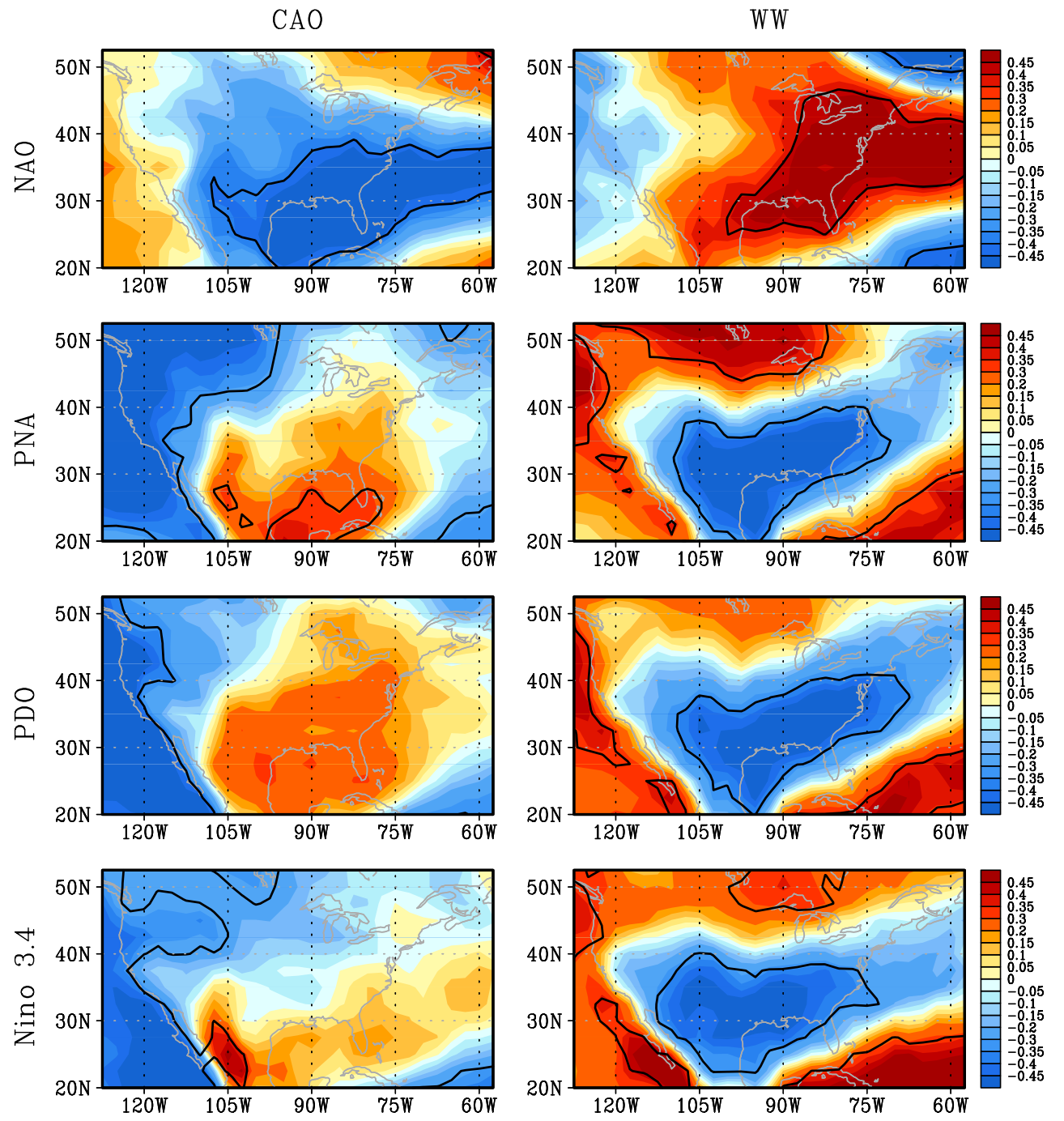

Fig. 4 Correlation between the local seasonal impact of cold days (left column) and warm days (right column) and the seasonal mean NAO (first row), PNA (second row), PDO (third row) and Niño 3.4

indices (fourth row) during winter, 1950-2011. The black contours encompass regions having correlations statistically significant at the $95 \%$ confidence level (figure from Westby et al. 2013)

both ENSO and the PDO project on the PNA pattern. Also, the prevalence of atmospheric blocking patterns is intrinsically linked to particular climate mode phases (Renwick and Wallace 1996).

There have been pronounced episodes of climate modes influencing ETEs during recent winters. Cold extremes over Europe and the southeastern United States during recent winters (2009-2010 and 2010-2011) were primarily accounted for by the anomalous blocking associated with persistent episodes of large amplitude negative phase of the NAO (Guirguis et al. 2011). There is also evidence of an important role for stationary Rossby wave patterns in contributing to North American temperature extremes during summer (Schubert et al. 2011; Wu et al. 2012). These wave patterns appear to arise from internal forcing associated with intraseasonal transient eddies (Schubert et al. 2011).

As discussed above, two more commonly recognized remote influences upon North American ETEs are associated with ENSO and the PDO (e.g., Westby et al. 2013), both involving local sea surface temperature anomalies and atmosphere-ocean coupling. These generally operate in conjunction with PNA-like teleconnection patterns that extend from the coupling region downstream into North America. Similar to the effect of climate modes, the impact of remote forcing upon warm season ETEs is partly limited by the relative inactivity and spatial extent of climate modes, which serve as horizontal pathways for Rossby wave energy between the remote forcing region and the local surface response (Schubert et al. 2011). 


\subsubsection{Connection to sea ice and snow cover}

The atmospheric response to the Arctic sea ice reduction is thought to be Arctic warming and destabilization of the lower troposphere, increased cloudiness, and weakening of the poleward thickness gradient and polar jet stream (Francis et al. 2009; Outten and Esau 2012). As the Arctic warms faster than lower latitudes (so-called Arctic Amplification), the meridional temperature gradient at higher latitudes is likely to weaken altering the polar jet stream according to thermal wind balance. Changes in the high latitude jet stream in turn have the potential to impact weather conditions at middle and high latitudes. For example, during winter an enhanced westerly jet over the North Atlantic can help maintain relatively mild conditions over northwest Europe via heat transport from the Atlantic. Cohen et al. (2014) review three "pathways" by which Arctic amplification may impact extreme weather events in mid-latitudes. In principle, Arctic amplification may lead to regional alterations in the structure of storm tracks, jet streams and planetary waves. In recent years, considerable attention has been focused on the role of Arctic amplification-induced changes to the jet stream (Francis and Vavrus 2012; Liu et al. 2012; Barnes 2013; Screen and Simmonds 2013). Francis and Vavrus (2012) found that a weaker zonal flow (i.e., polar jet) from weakened meridional temperature gradient slows the eastward Rossby wave progression and tends to create larger meridional excursions of height contours and associated temperature displacements resulting in a higher probability of extreme weather. In a similar vein, Liu et al. (2012) argue that the circulation change due to the decline of Arctic sea ice leads to more frequent events of atmospheric blocking that cause severe cold surges over large parts of northern continents. Francis et al. (2009), Overland and Wang (2010), Jaiser et al. (2012) and Lim et al. (2012) found that there is a delayed atmospheric response to the Arctic sea ice. Specifically, the Arctic sea ice extent in summer to fall influences the atmospheric circulation in the following winter over the northern mid- to high-latitudes, affecting the seasonal winter temperature and subseasonal warm/cold spells. Evidence presented in more recent studies (Barnes 2013; Screen and Simmonds 2013), however, suggests that the role of the mechanism put forth by Francis and Vavrus (2012) is uncertain at best. More generally, Cohen et al. (2014) conclude that our understanding of the mechanistic link between ongoing Arctic amplification and mid-latitude extreme weather is currently limited by shortcomings in relevant data records, physical models and dynamical understanding, itself. As such, the likely future impact of Arctic amplification upon extreme weather is highly uncertain.

Arctic amplification is also linked to long-term variability in high latitude snow cover. An analogous linkage between autumnal variability in Eurasian snow cover and wintertime ETE events over North America has been noted (Cohen and Jones 2011). In this case, autumnal snow cover anomalies induce a subsequent weakening of the stratospheric polar vortex during winter which, in turn, leads to a persistent negative phase episode of the tropospheric AO favoring North American cold events (Cohen et al. 2007). In addition, there is evidence that the changing Arctic sea ice extent may be linked to changes in the autumnal advance in Eurasian snow cover (Cohen et al. 2013). As for Arctic amplification, however, there is considerable uncertainty regarding the statistical robustness and physical nature of the Eurasian snow cover influence upon midlatitude extreme weather (Peings et al. 2013; Cohen et al. 2014).

\subsubsection{Large-scale climate "markers" for climate model assessment}

Representation of fundamental climate modes One obvious essential minimum requirement for climate models to properly represent the modulation of ETEs by climate modes is the extent to which the models are able to represent the primary climate modes, themselves. Thus, fundamental markers for model assessment are metrics that measure the representation of key extratropical climate modes including those internally forced on intraseasonal time scales (PNA, $\mathrm{AO} / \mathrm{NAO}$ and atmospheric blocking) and those externally forced on longer time scales (the extratropical response to ENSO and the atmospheric part of the PDO). Atmospheric models have had historical difficulty in representing some types of intraseasonal low frequency variability (Black and Evans 1998). A particular problem is an under-representation of atmospheric blocking activity (Scaife et al. 2010). In a similar vein, the representation of externally forced extratropical modes connected to ENSO and PDO depends on how well the coupled climate models simulate the associated oceanic phenomenological behavior.

The Coupled Model Intercomparison Project (CMIP) provides an ideal resource for assessing the ability of modern coupled climate models to represent the behavior of climate modes. A recent analysis of CMIP5 models indicates that while most models studied perform well in representing the basic aspects of the PNA pattern, a small subset of models have difficulty qualitatively replicating the NAO pattern (Lee and Black 2013; Table 4). Otherwise differences among model patterns consist of horizontal shifts or amplitude variations in the circulation anomaly pattern features. CMIP5 models generally underestimate the regional frequency of winter blocking events while summertime blocking events occurring over the high latitude oceanic basins are typically overestimated (Masato et al. 2013). Conversely, Westby et al. (2013) found serious deficiencies 
Table 4 Correlation coefficients between the loading pattern of observation and that of each CMIP5 model for NAO-like and PNAlike modes

\begin{tabular}{llll}
\hline Model & NAO & PNA & Mean \\
\hline GFDL-ESM2G & 0.94 & 0.93 & 0.93 \\
MPI-ESM-LR & $\mathbf{0 . 8 3}$ & $\mathbf{0 . 9 2}$ & $\mathbf{0 . 8 8}$ \\
HadCM3 & 0.90 & 0.82 & 0.86 \\
CSIRO-Mk3-6-0 & 0.85 & 0.81 & 0.83 \\
CCSM4 & 0.71 & 0.91 & 0.81 \\
CanESM2 & 0.73 & 0.83 & 0.78 \\
CNRM-CM5 & 0.78 & 0.77 & 0.78 \\
MIROC-ESM-CHEM & $\mathbf{0 . 7 3}$ & $\mathbf{0 . 7 8}$ & $\mathbf{0 . 7 5}$ \\
inmcm4 & 0.72 & 0.76 & 0.74 \\
NorESM1-M & 0.56 & 0.91 & 0.73 \\
IPSL-CM5A-MR & $\mathbf{0 . 6 1}$ & $\mathbf{0 . 8 4}$ & $\mathbf{0 . 7 3}$ \\
MIROC5 & 0.68 & 0.77 & 0.73 \\
HadGEM2-CC & $\mathbf{0 . 7 4}$ & $\mathbf{0 . 7 0}$ & $\mathbf{0 . 7 2}$ \\
MIROC-ESM & $\mathbf{0 . 7 2}$ & $\mathbf{0 . 7 0}$ & $\mathbf{0 . 7 1}$ \\
IPSL-CM5A-LR & $\mathbf{0 . 4 8}$ & $\mathbf{0 . 8 8}$ & $\mathbf{0 . 6 8}$ \\
MRI-CGCM3 & $\mathbf{0 . 4 9}$ & $\mathbf{0 . 8 7}$ & $\mathbf{0 . 6 8}$ \\
& 0.72 & 0.83 & 0.77 \\
\hline
\end{tabular}

Right-most column includes the averaged coefficients of two modes. Bold values denote high-top models and italic values denote low-top models (reproduced from Lee and Black 2013)

in the representation of the PDO by CMIP5 models with direct impacts upon the modulation of anomalous temperature regimes.

Regional flow parameters impacting remote dynamical communication The pathway between anomalous remote forcing and the regional circulation response involves several distinct factors. For example, in the case of the extratropical response to tropical heating anomalies, tropical divergent outflow interacts with subtropical vorticity gradients to produce a Rossby wave train that extends into the extratropics (Sardeshmukh and Hoskins 1988). The forced Rossby wave train can then dynamically interact with the background extratropical mean flow (such as barotropic deformation in the jet exit region) and the midlatitude storm tracks leading to a "net" large scale circulation pattern extending from the tropics into the midlatitude region of interest (e.g., Franzke et al. 2011). The ability of coupled climate models to accurately represent such pathways is dependent upon a concomitant representation of several regional atmospheric phenomena and circulation structures including:

1. The tropical large-scale circulation response to tropical diabatic heating

2. Upper tropospheric meridional vorticity gradients in the subtropics
3. Barotropic deformation structures in the jet exit regions

4. The structure and intraseasonal variability of the Atlantic and Pacific storm tracks

The authors recommend that model validation activities concentrate upon the above features in order to uncover likely sources for existing model deficiencies in leading teleconnection patterns.

\subsection{Dynamics of LSMPs}

\subsubsection{Diagnostic tools to study dynamics of LSMP onset/ decay}

The onset and decay of LSMP structures linked to ETEs generally occur on relatively short time scales. As such, the range of dynamical forcing mechanisms that can directly account for LSMP time evolution is limited to internal atmospheric processes (given the relatively long time scales associated with boundary forcing). The atmospheric processes affecting LSMP evolution can be local or remote. For example, local synoptic-scale cyclogenesis can usher in a regional Arctic air outbreak while a transient episode of the PNA teleconnection pattern can provide a remote downstream influence on North American extremes. In some cases it is an optimal juxtaposition of local and remote influences operating on multiple time scales that is required to produce an extreme event (e.g., Dole et al. 2014).

Most ETE events are associated with lateral air mass excursions, which are induced by large-scale circulation anomalies in the lower troposphere forming the LSMP (e.g., Loikith and Broccoli 2012). The anomalous circulation serves as a "dynamical trigger" for ETE events. The delineation of LSMP dynamics is treated as a two-stage process: First it is of interest to assess whether the main energy source(s) are local or remote. Once the energy source location is determined, the second stage is to assess the specific physical mechanism providing the proximate energy source in this location. An effective means for assessing the source location regions for large-scale atmospheric waves is the application of wave activity flux analyses (Plumb 1985; Takaya and Nakamura 2001). The wave activity flux is parallel to Rossby wave group velocity and traces out a threedimensional pathway between a wave source region (of flux divergence) and a wave sink region (of flux convergence).

Possible primary physical mechanisms providing wave activity sources in this context include large-scale barotropic growth, baroclinic growth/instability and nonlinear forcing by synoptic-scale eddies (Evans and Black 2003). These mechanisms may be augmented via secondary feedbacks related to internal diabatic processes or interactions of the LSMP with the local topography or land surface. Past studies have introduced comprehensive dynamical frameworks 
for studying the dynamical mechanisms leading to the growth and decay of large-scale circulation anomalies (e.g., Feldstein 2002, 2003). These are based upon a local analysis of tendencies in either the geopotential (Evans and Black 2003) or streamfunction (Feldstein 2002) fields. In these studies local tendencies are decomposed into separate forcing terms that can be related to distinct physical processes. The two-stage process outlined above is a generally useful means for the dynamical diagnosis of LSMP life cycles in both observations and climate model simulations.

\subsubsection{North American Arctic air mass formation}

Both dynamics and thermodynamics have roles in the formation of extreme cold-air masses. Wexler $(1936,1937)$ postulated that the cold air was formed at the surface by radiative cooling from a snow-covered ground under clear, windless conditions, creating an intense temperature inversion restricted to a very shallow layer at the surface. Finding that the Wexler model could not adequately explain the depth of the cold layer observed in soundings, Gotaas and Benson (1965) showed that the existence of suspended ice crystals were crucial to upper-level cooling. Curry (1983) later modeled the effect with the introduction of condensate, particularly ice-crystals, in the layer. In an experiment without moisture, the inversion that formed after 2 weeks of radiative cooling was less than 1000 meters deep. Only with the addition of ice crystals did the inversion rise above $900 \mathrm{hPa}$. More recently, Emanuel (2009) found that the rates and depth of cooling in his model were sensitive to the amount of water vapor and clouds present.

Turner and Gyakum (2011), in their composite study of 93 Arctic air mass formations in Northwest Canada, found that the cold air mass lifecycle is a multi-stage set of processes. During the first stage, snow falls into a layer of unsaturated air in the lee of the Rockies, causing moisture increases in the sub-cloud layer. Simultaneously, the midtroposphere is cooled by cloud-top radiation. On the second day, snowfall abates, the air column dries and clear-sky surface radiational cooling prevails, augmented by the high emissivity of fresh snow cover. The surface temperature falls very rapidly, as quickly as $18{ }^{\circ} \mathrm{C} \mathrm{day}^{-1}$. On the third day, after near-surface temperatures fall below their frost point, ice crystals and, nearer the surface, ice fog form. At the end of formation, there is cold-air damming (Forbes et al. 1987; Fritsch et al. 1992), with a cold pool and anticyclone in the lee of the Rockies, lower pressure in the Gulf of Alaska and an intense baroclinic zone oriented northwest to southeast along the mountains.

Figure 5 shows an event having extremely cold surface temperatures and unusual duration (17 days, compared with Turner et al., 2013, 93-case mean of 5 days). SLP anomalies tend to be higher near the coldest air, but are

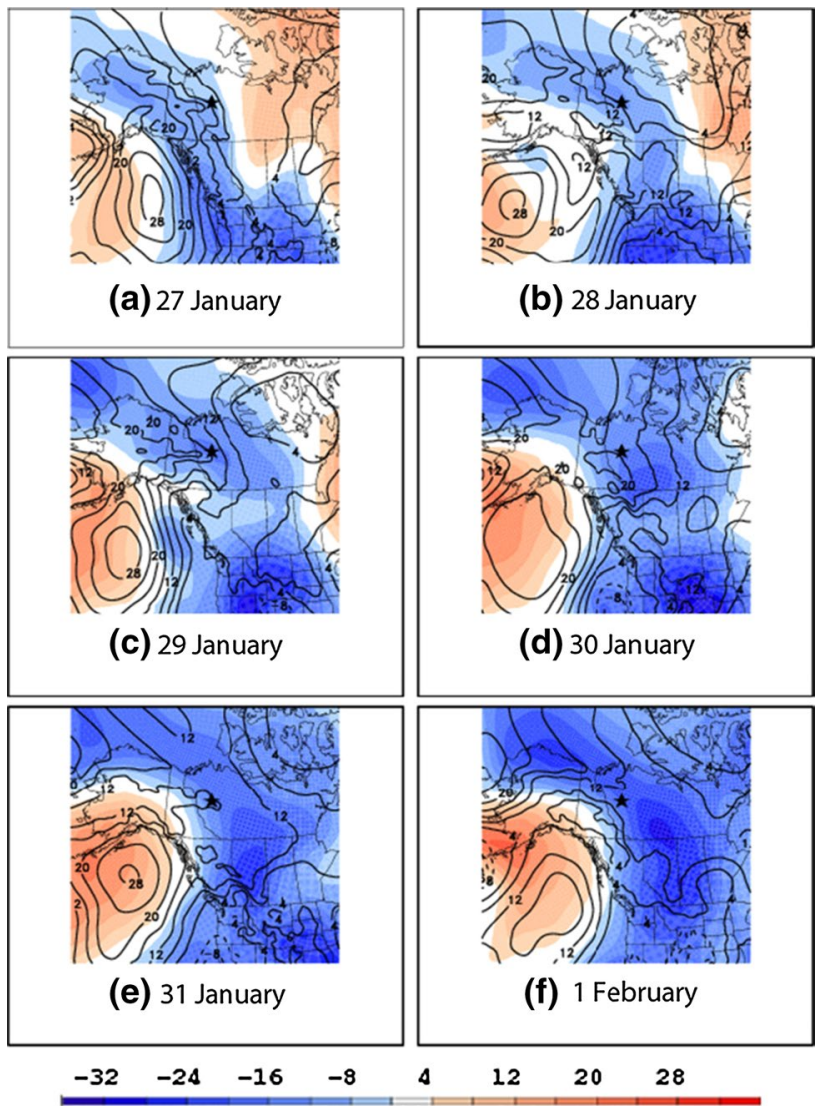

Fig. 5 Sea-level pressure anomalies (solid/dashed contour interval of $4 \mathrm{hPa}$ indicating positive/negative values) and 1000-500 hPa thickness anomalies (shaded, dam) at 1200 UTC during the arctic air mass formation period of 27 January 1979 through 1 February 1979. The Norman Wells, NWT rawinsonde station is indicated by the star; by 8 February the temperature there reaches $-48.1^{\circ} \mathrm{C}$. The climatological reference period is $1970-2000$

not extreme during this 5-day formation period. More to the point, the rapid $1000-500 \mathrm{hPa}$ cooling of $\geq 10{ }^{\circ} \mathrm{C} \mathrm{(} \geq 20$ dam) over northwestern Canada is noteworthy. Surface ridging that builds southeastward along the eastern slopes of the Rockies, particularly during 31 January and 1 February, facilitates cold-air damming and areal expansion of anomalously cold air southward to the US-Canada border. Turner et al. (2013) invoke diabatic cooling to explain the observed cooling during this formation period. This cooling may consist of sublimational cooling from precipitation falling into a dry layer and radiational cooling from suspended ice crystals. Turner et al. cite empirical evidence that much of the surface weather in this region and period includes snowfall, ice crystals, and ice fog.

\subsubsection{CONUS wintertime cold air outbreaks}

Cold air outbreaks over North America typically consist of a two-stage process: the first stage is the formation of 

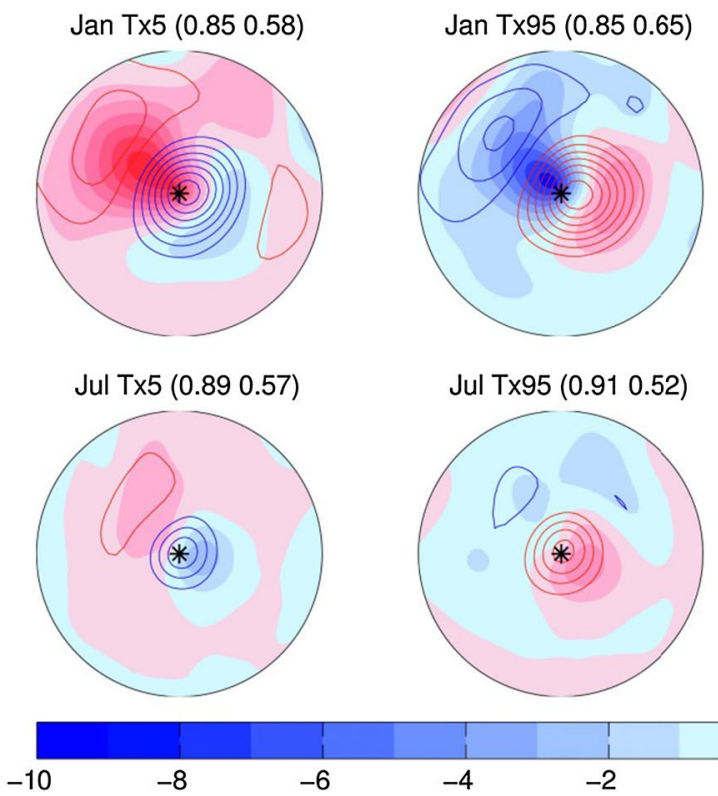
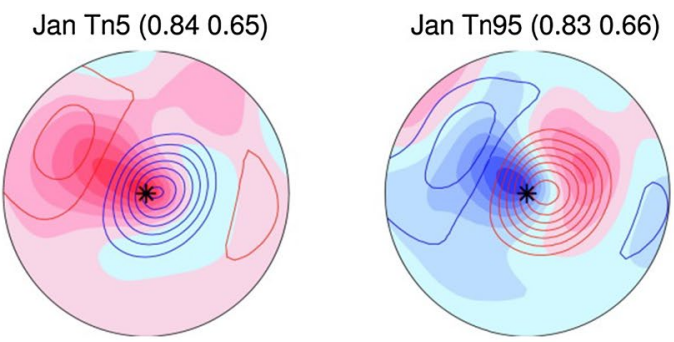

Jul Tn5 (0.86 0.55)
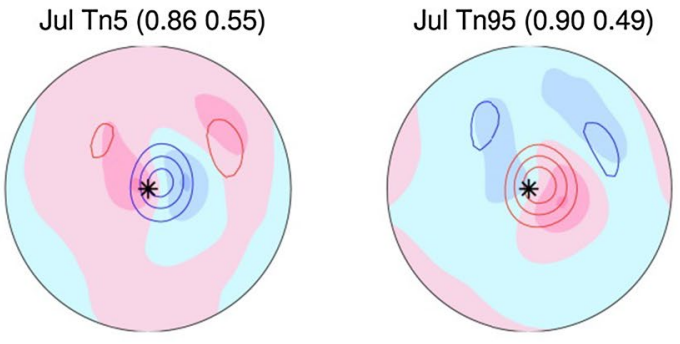

6

8

and warm minimum (Tn95) temperatures. The Grand composite combines information from extreme temperature events occurring at multiple disparate geographical locations over North America. The anomaly fields are displayed for a circular domain with a radius of $4500 \mathrm{~km}$. From Loikith and Broccoli (2012; see text for further details)

demonstrate an additional statistically significant modulation of ETEs by larger-scale teleconnection patterns.

West coast events (e.g., CA Central Valley events) Compared with cold air outbreaks affecting the eastern and central parts of the US, less has been written about outbreaks affecting the western US. Extreme cold over California is related to a large scale pattern that brings cold air from the Arctic and northern Canada without crossing the Pacific, and hence over the Rocky Mountains (Grotjahn and Faure 2008). As discussed in Grotjahn and Faure, the large scale pattern is similar to outbreaks affecting the areas east of the Rockies however with a primary difference being a small but statistically significant ridge over the southeastern US (see Fig. 2a, b). This ridge precedes the CAO by several days, including the large ridge that develops subsequently over Alaska. A cold air mass between these ridges is directed further westward (a more northerly or northeasterly flow of the cold air) than for eastern CAOs. The distortion of the flow by that southeastern ridge enables the cold air mass to cross the Rockies. Loikith and Broccoli (2012) capture a portion of this pattern in geopotential heights at $500 \mathrm{hPa}$ using their 'grand composite' technique. More local to the area of the extreme, colder temperatures are associated with an adjacent surface high (e.g. the conceptual model of Colle and Mass 1995). Favre and Gershunov (2006) pursue this link to anticyclones affecting western North America; and develop indices based on frequency 
and central pressure of transient cyclones and anticyclones in the eastern North Pacific. Their ' $\mathrm{CA}$ ' index is the difference, cyclone minus anticyclone, in strength and frequency. Negative CA values are correlated with the coldest $10 \%$ of winter minimum temperatures.

Eastern US events (i.e., east of Rockies) Several statistical and synoptic studies either directly or indirectly relate to the topic of US CAOs occurring east of the Rockies (e.g., Konrad and Colucci 1989; Colle and Mass 1995; Konrad 1996; Walsh et al. 2001; Cellitti et al. 2006; Portis et al. 2006). Common precursors to eastern CAO events include anomalously high surface air pressure over western Canada (linked to a polar air mass), occurrences of the negative (positive) phase of the NAO (PNA) teleconnection pattern and/or an anomalously weak stratospheric polar vortex. $\mathrm{CAO}$ onset is characterized by the south/southeastward advection of the polar air mass in association with one or more of the following synoptic LSMP features: southward extension or propagation of the surface high pressure from Canada, surface cyclogenesis over the eastern US, anomalously low $500 \mathrm{hPa}$ geopotential heights over the Great Lake region and the southeastward movement of an upper level shortwave from Canada.

Distinguishing between east coast (EC) and Midwest (MW; just east of the Rockies) CAO events, EC events result from the geostrophic cold advection enhanced by southeastward propagation of the surface high pressure system (with winds often amplified by surface cyclogenesis further east) leading to detachment of the polar air mass from its source (Konrad and Colucci 1989; Walsh et al. 2001). MW events are linked to the southeastward meridional extension of surface high pressure from Canada leading to unusually lengthy cold air transport (Walsh et al. 2001). For MW events occurring just east of the Rockies, the cold advection is related to low-level northerly ageostrophic flow within a region of cold-air damming against the topography (Colle and Mass 1995). In all cases, the salient LSMP features are synoptic-scale in nature and, thus, governed by generally well-understood dynamical physical principles considered to be well-represented by weather and climate models. The CAO process, itself, is largely due to radiative cooling (during polar air mass formation and early stages of CAO onset) and southward air mass transport (by the horizontal wind) partly offset by adiabatic warming induced by large-scale subsidence (Konrad and Colucci 1989; Walsh et al. 2001; Portis et al. 2006). Although the proximate physics associated with the CAO process itself is reasonably well characterized, our knowledge of the physics of the LSMP patterns is implicit and depends on subjective associations (between advective circulation features and synoptic LSMPs) that have been made in earlier studies. As such, there is an existing need to (a) more objectively link critical advective CAO circulation features to dynamical entities (e.g., potential vorticity) and (b) subsequently assess the physical origin of these dynamical entities.

\subsubsection{Summer heat wave events}

Hot spells over North America have an intense upper level ridge as one expects hydrostatically. This ridge is seen in Figs. 2 and 6. There can also be a shallow layer of relatively lower pressure, sometimes called a 'thermal low'. Hot spells occur from a combination of factors: a hot air mass displaced from its normal location (displaced from the southwestern desert), strong subsidence (causing adiabatic warming), and solar heating. Solar heating is more effective when surface latent heat fluxes are constrained (by drought, for example). The first two factors are enhanced and help define the LSMP for a hot spell; there may be an upstream trough (e.g. Figs. 2, 6) that enhances southwesterly advection of warmer air. Other factors influence how the LSMP develops. What follows are details for different regions of North America.

West coast events Heat waves affecting the west coast are linked to an upper air LSMP that has a local ridge. For California Central Valley heat waves, that ridge is typically aligned with the west coast and the LSMP also has upstream features: a trough south of the Gulf of Alaska and a ridge further west, south of the Aleutians (Grotjahn and Faure 2008) (see Fig. 2d). The local ridge is easily understood as resulting from high thickness due to the anomalous high temperatures through the depth of the troposphere generally centered along the west coast of the US. (Plots can be found here: http://grotjahn.ucdavis.edu/ EWEs/heat_wave/heat_wave.htm) Grotjahn and Faure also show that a statistically significant ridge in the northwest Pacific develops prior to the significant intensification of that west coast ridge. These features are essentially equivalent-barotropic through the depth of the troposphere. While Grotjahn and Faure found variation amongst the events, the ensemble average consists of a significant temperature anomaly that in the lower troposphere $(850$ and $700 \mathrm{hPa})$ is located just off the Oregon and northern California coast and elongated meridionally. The narrow zonal with longer meridional scale is consistent with station data analyzed by Bachmann (2008). Bachmann found that extreme surface temperature dates in Sacramento were more frequently matched by corresponding extreme dates at many stations located west of the Sierra Nevada and Cascades mountain ranges than closer stations east of the mountains. Grotjahn (2011) shows that the temperature anomaly leads to a thermal low being at the coast that sets up a low level pressure gradient that opposes penetration by a cooling sea breeze. The lower and mid-tropospheric flow has anomalous significant easterlies that are also downslope over some regions, 

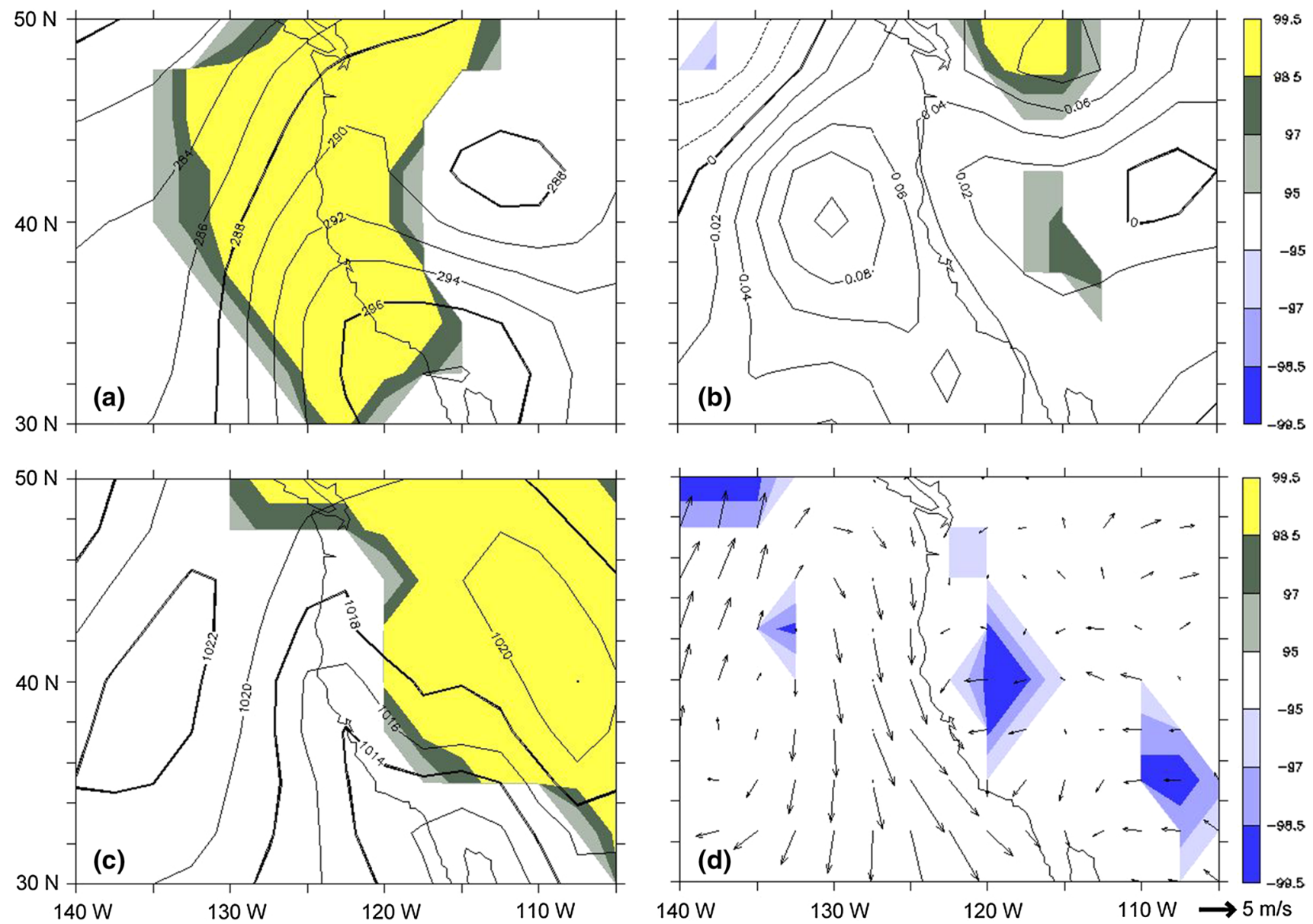

Fig. 7 Composite synoptic weather patterns at the onset of the 14 Sacramento California summer (JJAS) heat waves studied by Grotjahn and Faure (2008). a Temperature at $850 \mathrm{hPa}$ with a $2 \mathrm{~K}$ interval. b $700 \mathrm{hPa}$ level pressure velocity with $2 \mathrm{~Pa} / \mathrm{s}$ interval and where positive values mean sinking motion. c Sea level pressure with $2 \mathrm{hPa}$ interval, $\mathbf{d}$ Surface wind vectors with shading applicable to the zonal

component. Areas with yellow (lighter inside dark) shading are positive (above normal) anomalies that are large enough to occur only $1.5 \%$ of the time by chance in a same-sized composite; areas that are blue (darker inside light) shading are negative anomalies occurring only $1.5 \%$ of the time

most notably the Sierra Nevada mountains. Finally, there is notable sinking that lowers the climatological subsidence inversion and hence sunlight rapidly heats up the shallow layer beneath. (These factors are seen in Fig. 7).

Gershunov et al. (2009, hereafter GCI) make the novel distinction of considering separately heat waves that have high daytime maximum and events with high nighttime minimums. In so doing they uncover an LSMP with unusually high values of precipitable water $(\mathrm{PW})$ over their region of interest occurring during their 'nighttime' heat waves (but not their 'daytime' events). GCI emphasize a trend of increasing occurrence of 'nighttime' events. Gershunov and Guirguis (2012) also find that trend in all their sub-regions of California and also show another trend: increasing longitudinal extent of Central Valley heat waves. GCI show maps of anomalous geopotential heights which also show the west coast ridge (height anomaly centered

over Washington State) with upstream (and downstream) troughs, consistent with Grotjahn and Faure. GCI show the LSMP for SLP (high over the Great Plains and low off the west coast) and remark that both daytime and nighttime events have a corresponding general southeasterly flow of air out of the desert southwest. This flow occurs throughout the lower troposphere with associated high frequency ( $<7$ day period) heat fluxes that are prominent just off the coast (Grotjahn 2015); and consistent with setting up the offshore pressure gradient (to oppose a cooling sea breeze).

For heat waves affecting the western areas of Washington and Oregon, Bumbaco et al. (2013, hereafter BDB) show an upper level $(500 \mathrm{hPa})$ ridge over the west coast and trough upstream over the Gulf of Alaska. That trough and ridge pattern is generally similar to the pattern for California heat waves, including the tropospheric height anomaly centered at the coast (Grotjahn 2011). Using a regression 
approach Lau and Nath (2012) find a ridge and trough further upstream (over the western North Pacific) that are stronger several days prior to the event onset; both the location and timing of the ridge and trough are similar to those shown in Grotjahn and Faure. Similar to Grotjahn (2011, 2013, 2015), BDB find the lower tropospheric temperature anomaly $(850 \mathrm{hPa})$ to be centered at the west coast of North America. Hence, BDB find negative values of sea level pressure anomaly centered offshore that sets up an offshore low level pressure gradient and offshore (northeasterly) flow (again similar to California heat waves). Consistent with the heat fluxes shown in Grotjahn (2015), the near-coast thermal trough appears to migrate from the southwestern deserts across the length of California to finally reach western Oregon and Washington (Brewer et al. 2012).

Midwest events Heat waves affecting the Midwest have anticyclonic flow at mid-levels, either as a closed anticyclone or as a strong ridge (Klein 1952; Karl and Quayle 1981; Namias 1982; Chang and Wallace 1987; Lyon and Dole 1995; Kunkel et al. 1996; Livezey and Tinker 1996; Palecki et al. 2001; Meehl and Tebaldi 2004; Lau and Nath 2012; Loikith and Broccoli 2012; Teng et al. 2013), with associated clear skies allowing maximum solar heating of the surface as well as adiabatic warming from subsidence.

For at least some events, the continental anticyclonic flow at mid-levels is part of a larger pattern of anomalies with remote centers over the Pacific and Atlantic (Namias 1982; Chang and Wallace 1987; Livezey and Tinker 1996; Lau and Nath 2012; Loikith and Broccoli 2012; Teng et al. 2013), with some suggestion that the anomalies are generated in the Pacific (Namias 1982; Lyon and Dole 1995; Livezey and Tinker 1996; Teng et al. 2013), with possible predictability (Teng et al. 2013). Teng et al. (2013) have noted the similarity of the circulation pattern to a Rossby wave number 5 wave train in the jet stream waveguide. The commonality of the wave train pattern structure and evolution among these studies is difficult to assess, though.

Studies of the surface flow have been less common, but negative SLP anomalies have been noted (Chang and Wallace 1987; Lau and Nath 2012; Loikith and Broccoli 2012), and Lau and Nath (2012) have shown anomalous southerly (or southwesterly) flow at the surface, consistent with strong horizontal warm advection. The regional-scale flow also interacts with local mechanisms, particularly the Urban Heat Island (UHI) effect (Kunkel et al. 1996; Palecki et al. 2001). Another common element identified in several studies is the presence of drought (Chang and Wallace 1987; Karl and Quayle 1981; Namias 1982; Lyon and Dole 1995) as well as simultaneous precipitation deficits (Lau and Nath 2012).

Eastern events While the large-scale meteorological patterns associated with heat waves in the eastern US have not yet seen much study, they have been examined for the Northeast and Central US Gulf Coast in Lau and Nath (2012) and for piedmont North Carolina by Chen and Konrad (2006). For both the Northeast and Gulf Coast, Lau and Nath found a mid-level ridge centered over the region as part of a wave train and precipitation deficits, broadly similar to the results for the Midwestern regions. For piedmont North Carolina, Chen and Konrad showed that, at upper levels, a strong ridge over or just upstream of the region was a common feature along with, at lower levels, adiabatic warming associated with descent from the Blue Ridge Mountains into the piedmont region.

\section{Modeling of temperature extremes and associated circulations}

Temperature extremes have some predictability at weather and climate time scales that can be exploited by models for short term predictions and long term projections. At weather time scales the predictability of North American extreme temperature events (ETEs) is largely dependent upon the nature of the LSMPs that help organize their occurrence. The greatest predictability is expected to occur during the boreal cool season when ETEs are, at least in part, influenced by low frequency modes (PNA, NAO and blocking events) (Westby et al. 2013) with intrinsic time scales of several days to weeks (Feldstein 2000). Loikith and Broccoli (2012) illustrated that the local LSMPs linked to ETEs generally exhibit synoptic spatial scales rather than planetary scales, though a wave train can be long (e.g. Grotjahn and Faure, 2008; Fig. 2). Given the essential role of synoptic-scale disturbances such as east coast cyclones and southward moving polar anticyclones over the Midwest (Konrad and Colucci 1989; Walsh et al. 2001) in ETEs, pointwise predictability of ETEs is ultimately limited by our ability to forecast the details of synoptic-scale phenomena several days in advance (Hohenegger and Schär 2007).

Hence a significant challenge for models to predict temperature extremes is their ability to predict or simulate synoptic scale phenomena, low frequency modes that provide a large-scale meteorological context, and small scale atmospheric processes and land surface processes that influence the surface heat fluxes. Both dynamical and statistical models have been developed and used to simulate and project changes in temperature extremes. This section briefly summarizes the methods and skills of the models, while analysis of observed trends and projections of future trends are summarized in Sect. 5.

\subsection{Global and regional climate model skill in simulating temperature extremes}

Both global and regional climate models have been used to elucidate processes contributing to ETEs and evaluate 
Fig. 8 Performance portrait of the CMIP5 models' ability to represent the temperature based ETCCDI indices over North American land. The colors represent normalized root mean square errors of seasonal indices compared to the ERA Interim reanalysis. Blue colors represent errors lower than the median error, while red colors represent errors larger than the median error. Seasons are denoted by triangles within each square. Models marked with "** are not included in the RCP8.5 projections. Root mean square errors normalized by the model median RMSE for 3 other reanalyses are shown in the rightmost columns for comparison

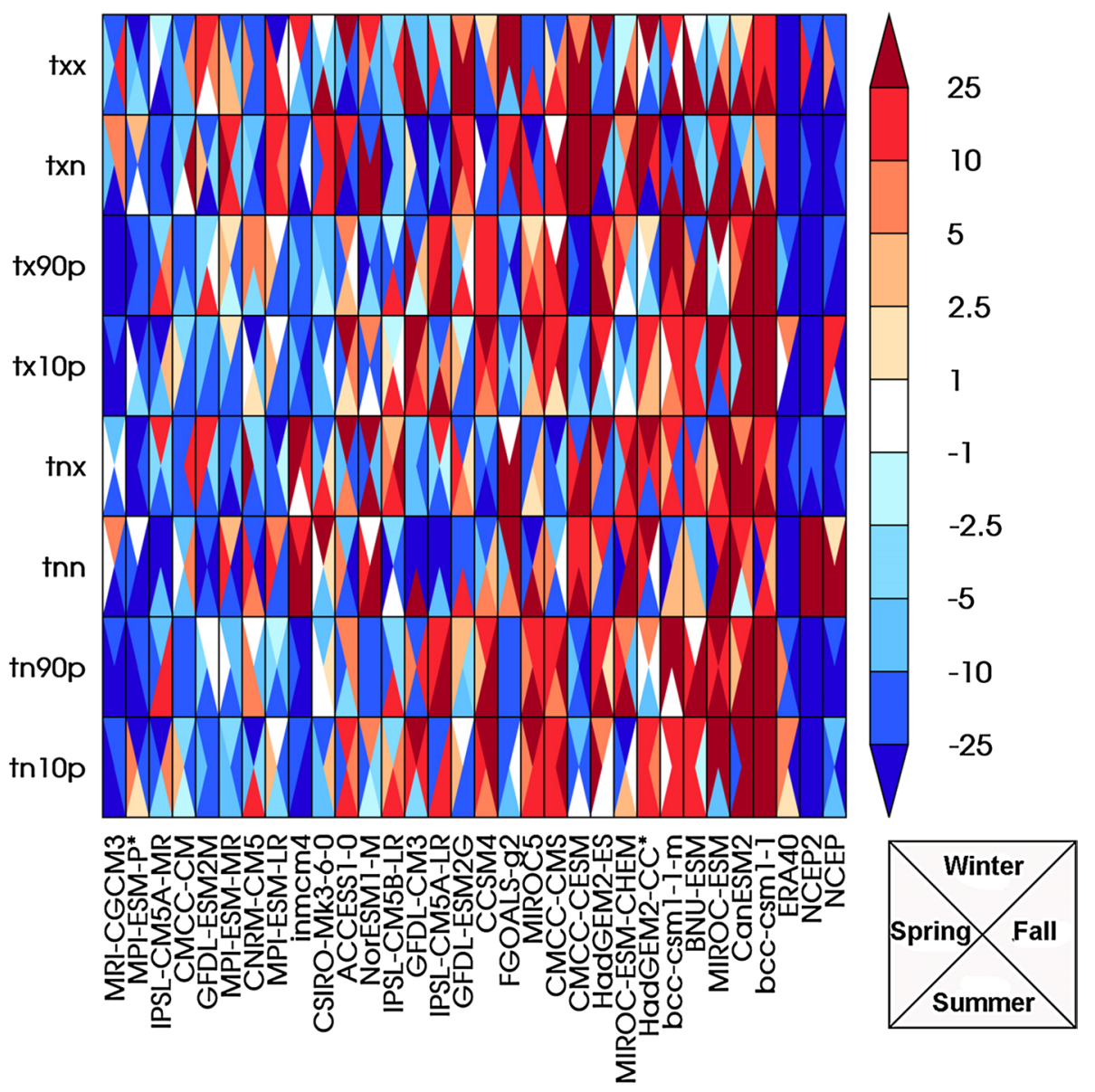

model skills. The ability of global models to reproduce the observed temperature extreme statistics has been assessed by Sillmann et al. (2013a, b), Westby et al. (2013) and Wuebbles et al. (2014) using CMIP5 multi-model ensembles. Figure 8 shows a performance portrait of the normalized root mean square errors over the North American land area from the 28 available CMIP5 "historical" models for eight temperature based ETCCDI indices over 1979-2005 compared to the ERA Interim reanalysis (Dee et al. 2011). As in Gleckler et al. (2008), to plot errors from multiple variables on the same scale, they are normalized by the median error of the CMIP5 models using the formula

$E_{j}^{R}=100 \times \frac{\left(E_{j}-E_{\text {median }}\right)}{E_{\text {median }}}$.

Here, $E_{\text {median }}$ is the median root mean square error (RMSE) of the CMIP5 models, $E_{j}$ is the RMSE of the $j t h$ model and $E_{j}^{R}$ is that model's "relative RMSE" and is plotted for seasonal means of the indices. In this analysis, the model median RMSE in Eq. 1 is calculated for each variable over all seasons and then applied to normalize each season in order to assess the relative seasonal performance. Blue colors represent errors lower than the median error, while red colors represent errors larger than the median error. Seasons are denoted by triangles within each square. The different models are arranged in order of increasing average relative error with the models with the lowest average relative error on the left. The average relative error is positive for all 8 indices as Fig. 8 has more deep red than deep blue colors even though the number of positive and negative relative errors is equal. Spring has significantly lower relative error (3.8\%) averaged across all models and variables, compared to winter (5.0 \%), summer $(5.2 \%)$ and fall $(5.8 \%)$.

To get a sense of model errors relative to the observational uncertainty, the 3 rightmost columns of Fig. 8, show the error of three other reanalyses considered in Sillmann et al. (2013a) relative to the model median RMSE. The two best models (leftmost in Fig. 8) are competitive with these other reanalyses but most models' RMSE relative to ERA Interim are significantly larger than the disagreement among reanalyses for many fields. Reanalysis disagreements in the cold night metrics (tnn, tn10p) and a cold day metric (tx10p) are notable and a larger number of models perform better in these fields relative to this crude measure of observational uncertainty.

Sillmann et al. (2013a) found that the spread amongst CMIP5 temperature extreme indices tends to be smaller than that of the CMIP3 models (earlier version of the 


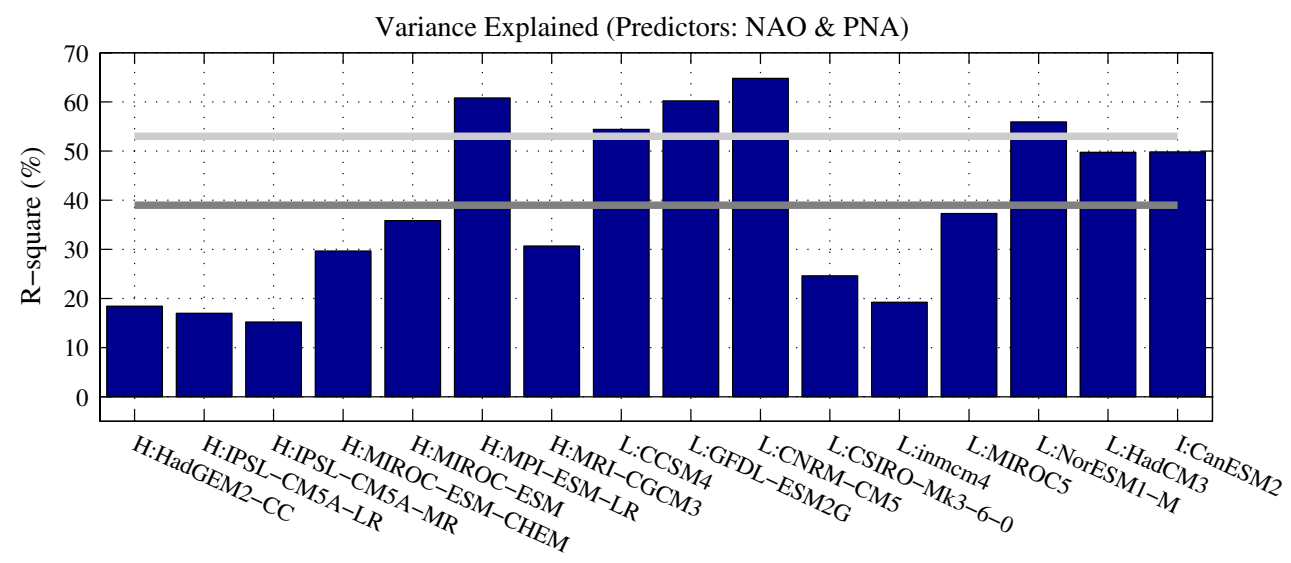

Fig. 9 The variance explained in an annual metric of the impact of wintertime Warm Waves on the southeast United States from a multiple linear regression using the NAO and PNA indices as predictors. Results are displayed for individual CMIP5 model simulations (blue

CMIP5), indicating reduced uncertainty. They identified an increase in the monthly maximum daily maximum temperature and a decrease in the monthly minimum daily minimum temperature by the CMIP5 models over the high northern latitudes, compared to CMIP3. Analysis of 20 year return values in the CMIP3 models by Zwiers et al. (2011) found that models tend to warm the minimum temperature less than observed and that they warm the maximum temperature more than observed over the latter half of the twentieth century.

Westby et al. (2013) analyzed reanalysis data and CMIP5 historical simulations to study the statistics and low frequency mode modulation of wintertime CAOs and warm waves (WWs) occurring over the continental United States during 1949-2011. The observational results indicate (a) a lack of significant long-term trends in ETE frequency and (b) a seasonal modulation of CAOs (WWs) by the NAO and PNA (NAO, PNA, ENSO and PDO) patterns (Fig. 4). Similar behavior is found in the CMIP5 models, showing CAOs are mainly modulated by NAO in the southeastern US and by PNA in the northwestern US, while WW frequency is modulated by NAO over the eastern US and by a combination of PNA, PDO and ENSO over the southern US. The study also found modest influence of ENSO on WWs over the southern US, in good agreement with Lim and Schubert (2011). Comparison of WWs and CAOs between the CMIP5 models and observation indicated that the models tend to overestimate WW frequency, but underestimate CAOs frequency, although using a larger ensemble of CMIP5 models, Gao et al. (2015) found a better agreement between CAO frequency from CMIP5 models and reanalysis datasets.

Overall, CMIP5 models properly represent many of the significant associations between ETEs and low frequency bars) while the light and dark gray lines denote variance values for observations and the model mean, respectively (from Westby et al. 2013)

modes, particularly the modulation by the NAO and PNA patterns. Similar to Lee and Black (2013) who noted model deficiencies in representing low-frequency variability, Westby et al. (2013) found that the CMIP5 models underestimated the collective influence of low-frequency modes on temperature extremes (e.g., Fig. 9). One notable model failure is the virtual absence of a seasonal modulation of ETEs by the PDO because models do not adequately represent the nature and physics of the PDO. On the other hand, CMIP5 models do a considerably better job in representing the general behavior of the NAO and PNA patterns (Lee and Black 2013). Westby et al. conclude that predictions of future ETE behavior are ultimately limited by the ability of state-of-the-art coupled climate models to properly represent the (evolving) behavior of prominent low frequency climate modes. Nonetheless, consistent with observations, little evidence of significant trends (in either WW or CAO frequency) is found in the model simulations over the continental US from 1949 to 2011.

Heat waves are associated with anomalous large-scale circulation patterns well resolved by GCMs. Grotjahn (2013, 2015) describe how the LSMPs for California hot spells simulated by a CMIP5 climate model compare with the observed LSMPs; while the model generates a similar large scale pattern and included the needed large scale sinking, the model is unable to simulate sea breezes so the effect of LSMP blocking of sea breezes during extreme heat episodes is likely not captured by the global model. In general, heat wave intensity and duration can vary at local to regional scales because surface temperature is influenced by processes such as land surface fluxes, turbulence and winds, and clouds and radiation. For example, land-atmosphere interactions were found to play an important role in European summer heat waves of the past decades (Fischer 
et al. 2007). Using a regional model, Jaeger and Seneviratne (2011) and Lorenz et al. (2010) highlighted the key role of soil moisture memory on heat wave intensity and persistence, respectively. Using observations and a CMIP3 model, Gershunov and Douville (2008) showed a strong negative relationship between preceding winter and spring precipitation and summertime heat in the central, Midwestern, and eastern US. In regions with limited soil moisture, surface temperature can respond more strongly to the largescale circulation anomaly that leads to clear sky and strong surface solar heating because surface cooling from evapotranspiration is limited. As soil moisture is influenced by antecedent precipitation and surface properties such as land cover, topography, and soil characteristics that vary at local to regional scales, heat wave intensity and duration can vary similarly, within the context of large-scale influence by a circulation anomaly. Thus the ability of climate models to simulate and predict heat waves is also dependent on physics parameterizations and grid resolution.

Lau and Nath (2012) analyzed GCM simulations performed at $200 \mathrm{~km}$ and $50 \mathrm{~km}$ grid resolutions and found considerable resemblance between the temperature anomaly patterns from the coarse and fine resolution simulations, except for some local details generated by the higher resolution model. Both models were able to capture realistic heat wave intensity, duration, and frequency in various key regions of North America and the synoptic features accompanying the warm episodes as revealed in the North American Regional Reanalysis. Kunkel et al. (2010) compared regional climate simulations performed at $30 \mathrm{~km}$ resolution over North America driven by two GCM historical simulations with the respective GCM simulations and observations. Although the two GCM simulations have opposite temperature biases, downscaling by the RCM provided improved simulations of heat waves in both cases, with the overall averaged biases reduced by a factor of two compared to the GCMs. Gao et al. (2012) compared a regional simulation at $4 \mathrm{~km}$ grid resolution over the eastern US driven by a GCM with observations and the GCM simulation. They found statistically significant improvements in heat wave intensity and duration in the regional simulation compared to the global simulation in 14 out of 16 states in the eastern US and attributed the improvements to high-resolution topography and land use information that impact local surface temperature.

In summary, global climate models have demonstrated useful skill in simulating heat waves and cold air outbreaks over North America and their linkages to low frequency variability such as NAO, PNA, and ENSO. However, models generally underestimate the combined influence of low frequency modes on temperature extremes, with PDO and its modulations on temperature extremes being most notably deficient. Although heat waves and their LSMP are well resolved by global models, some studies have demonstrated improved skill in simulating heat waves using regional models that may better capture regional processes such as land-atmosphere interactions influenced by surface heterogeneity.

\subsection{Statistical modeling of temperature extremes}

Most statistical methods for downscaling of temperature can be thought of as extensions of the model output statistics and related approaches to statistical weather forecasting (e.g., Wilks 2006). The most popular method is multiple regression analysis (e.g., Easterling 1999) but it cannot be expected to represent extremes well, as only the conditional mean of temperature given the values of the predictor variables (such as indices of LSMPs) is statistically modeled. In particular, the error term in the regression equation is usually assumed normally distributed, which is not necessarily realistic for temperature extremes.

Recently, bias correction techniques involving quantile mapping (Thrasher et al. 2012), or quantile matching (Ho et al. 2012), have become a popular way to adjust the entire probability distribution of temperature. Because of the mismatch in spatial (and sometimes temporal) scales involved in downscaling, the downscaled temperatures typically do not possess high enough variance. This issue is crucial for extremes, with it being preferable to increase the variance through randomization rather than direct "inflation" (Maraun 2013; von Storch 1999). Ideally, quantile mapping for the extreme tails of the temperature distribution should use statistical methods based on extreme value theory (e.g., Coles 2001). Kallache et al. (2011) proposed such a method, in which the quantile mapping involves fitting the Generalized Pareto distribution (GPD) to the upper (or lower) tail of the distribution. Although their application was to precipitation extremes, the technique should apply equally well to temperature extremes.

The statistical methods for relating extreme temperatures to LSMPs and climate modes, described earlier in Sect. 2, could also be applied in the context of statistical downscaling. In this approach, the extremal distribution (GEV or GPD) is conditioned on indices of LSMPs or climate modes, as well as possibly on other covariates in the context of statistical downscaling. Brown et al. (2008) relate daily maximum and minimum temperatures to the NAO index; Sillmann et al. (2011) relate European CAOs to a blocking index; Katz and Grotjahn (2014) relate California hot spells to an associated LSMP index. The chief limitation is that, given the effective reduction in data when only considering extremes, not as many predictors necessarily could be included as in more conventional statistical downscaling. 


\section{Observed and projected trends of temperature extremes}

\subsection{Observed trends and variability}

Traditional methods in climate research for detecting trends in temperature extremes tend to focus on the relative frequency of exceeding a high threshold or of falling below a low threshold, as well as indices derived from such rates (Karl et al. 1996; Gleason et al. 2008). Such approaches generally fail to give a complete picture of trends in temperature extremes as they neglect the intensity of the event. It should be noted that other forms of indices are also commonly used to monitor changes in temperature extremes (Zhang et al. 2011).

Extreme value statistics (Coles 2001) formally account for both the rate of exceeding a high threshold and in the excess over a high threshold so they can be applied to detect trends in each of these two components (Katz 2010).A fundamental result in extreme value theory is that block maxima (e.g., highest daily maximum temperature each summer), suitably normalized, have an approximate generalized extreme value (GEV) distribution. In practice, it is more efficient and can be more informative to fit the GEV indirectly using the peaks over threshold (POT) approach, which involves a Poisson distribution to approximate the rate of exceeding a high threshold; and a generalized Pareto (GP) distribution to approximate the excess over the high threshold. Possible trends in extremes can be introduced into these extreme value distributions with time as a covariate. That is, the location, scale, and shape parameters of the GEV (or, equivalently, the rate parameter of the Poisson distribution and the scale and shape parameters of the GP distribution) can shift with time (Coles 2001). See Brown et al. (2008) for examples of the application of the POT approach to trend analysis of temperature extremes.

Peterson et al. (2013) applied the POT approach with a threshold corresponding to the 99th percentile for the upper tail (or 1st percentile for the lower tail) specific to each grid point in the US. To avoid temporal dependence of extremes, only the single highest (or lowest) daily temperature within a run of consecutive days exceeding the threshold was retained (termed "runs declustering"). Using the equivalent parameterization in terms of the GEV distribution, a linear trend in the location parameter of the GEV was fitted by the technique of maximum likelihood (Coles 2001), assuming that the scale and shape parameters were constant over time. To adjust for seasonality, the analysis was performed in terms of daily anomalies.

Figure 1 shows the estimated change in 20-yr return levels between 1950 and 2012, along with an indication of statistical significance. The broadest region of warming occurs for the cold tail of minimum temperature (panel

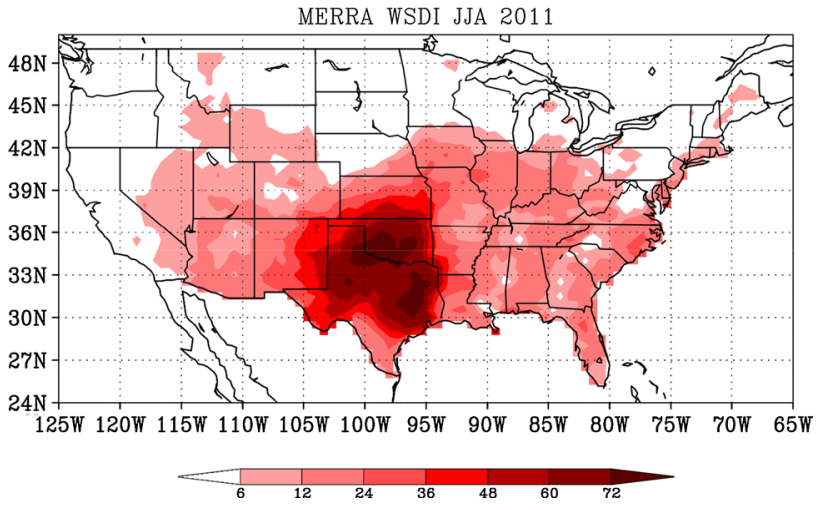

Fig. 10 Warm Spell Duration Index from MERRA for 2011 summer over the United States. WSDI is computed from the 90th percentile of daily mean temperatures for the summer season

d). Cooling occurs in the upper tail of both daily maximum (panel a) and minimum (panel c) temperature in the southeastern US. Although these results are not explicitly in terms of heat waves or cold air outbreaks, they do reflect changes in extremes that are often part of such multi-day events (Furrer et al. 2010).

Atmospheric reanalyses have provided a significant source of data for weather and climate research because they assimilate multitudes of available observing systems and provide continuous fields for regions or variables with sparse or no direct observations. Utilizing reanalyses in the calculation of extreme indices should be approached with a strong validation strategy (as discussed in Zhang et al. 2011). In the case of temperature, processes near the surface can influence the distribution of temperature. However, Simmons et al. (2010) show that ERA Interim reanalysis surface temperature reproduces that of HadCRUTv very closely, owing to the correction of soil water by the analysis of near-surface atmospheric water and temperature. Further, Bosilovich (2013) shows that even without surface analysis, reanalyses can provide robust interannual variability of seasonal surface temperature at regional scales. Furthermore, reanalysis temperature, augmented with observations, can provide a substantially improved representation of the diurnal cycle of temperature (maximum and minimum) consistently over the global land mass (Wang and Zeng 2013).

Two reanalyses, the modern-era retrospective-analysis for research and applications (MERRA) (Rienecker et al. 2011) and the climate forecast system reanalysis (CFSR) (Saha et al. 2010) have stored data at hourly intervals that allow evaluation of the diurnal cycle, especially maximum and minimum temperatures that are important to extreme temperature events. Figure 10 shows the US summertime 2011 Warm Spell Duration Index (WSDI, e.g. Alexander et al. 2006) computed from the occurrences of daily mean 


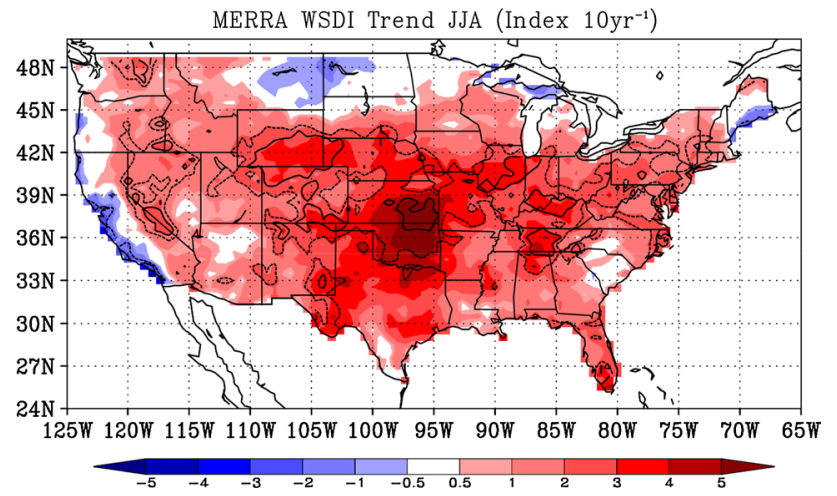

Fig. 11 Trend in WSDI as determined from MERRA for US summertime temperatures. Dashed and solid black contours indicate statistical significance (at 90 and $95 \%$ confidence respectively)

temperature exceeding the 90th percentile for 6 days or longer from MERRA. This diagnostic relies on continuous data to derive the seasonal index, but also identify the spatial extent. Figure 11 shows the US trends in WSDI from MERRA. Positive trends are apparent in many areas of the US with some regions having statistical significance (above $90 \%$ confidence).

Walsh et al. (2001) used global reanalysis data to study cold air outbreaks and identified Midwest, Gulf Coast, and East Coast as regions influenced by CAOs. They did not identify any apparent trend in CAOs in North America between 1948 and 1999, although analysis from a single station suggests that extreme outbreaks may have been more frequent in the late 1800s and early 1900s. Extending the study to include the recent decade from the global reanalysis data may provide further confidence in potential trends in CAOs in North America.

The twentieth century reanalysis (Compo et al. 2006, 2011) provides objectively analyzed four-dimensional data on a $2^{\circ}$ global grid. With assimilation of synoptic surface pressure available since the late nineteenth century, this dataset covers the period from 1871 to 2012 and offers a unique opportunity for analysis of long-term trend in temperature extremes and the associated LSMP. Compo et al. (2011) showed encouraging comparison of this surfacebased reanalysis product with other reanalyses that make use of upper-air and satellite data. Future work utilizing this dataset could potentially further advance understanding of variability and trends in LSMPs that influence temperature extremes.

\subsection{Projected trends}

The CMIP3 and CMIP5 multimodel ensembles have been used to investigate projected changes of temperature extremes for the next couple of decades (e.g., mid-twentyfirst century) (e.g., Tebaldi et al. 2006; Orlowsky and Seneviratne 2012; Sillmann et al. 2013b; Wuebbles et al. 2014). Climate change simulations in the CMIP5 multimodel ensembles showed greater changes in ETCCDI based on daily minimum temperatures than in ETCCDI based on daily maximum temperatures. Also, the strong emission scenario such as representative concentration pathways (RCPs) 8.5 (Moss et al. 2010; van Vuuren et al. 2011) produced more definitive changes in temperature extreme statistics than weaker emission scenarios (e.g., RCP 2.6 and 4.5). Furthermore, the changes in ETCCDI under RCP8.5 tend to be greater than changes under any of the scenarios in the special report on emission scenarios (SRES) (Nakicenovic et al. 2000) used in CMIP3. The spatial distributions of Sillmann et al. (2013b) showed that the northern high latitude regions have the strongest increase in the minimum daily minimum temperature, while changes in the maximum daily maximum temperatures tend to be evenly distributed globally. The study also noted that the percentile indices such as warm and cold nights, exhibit the highest increases in the tropical regions. This is a result of differences in interannual temperature variability between the two regions, which is relatively large in mid- to high latitudes but small in the low-latitudes.

Figure 12 shows the projected ensemble mean increase in two of the ETCCDI indices assessed in Fig. 8 at the end of this century (2080-2100) from the reference period of 1985-2005 under the RCP8.5 forcing scenario of the 5th assessment report of the intergovernmental panel on climate change (IPCC AR5). Twenty-six models are included in this multi-model average. Models marked with an "*" in Fig. 8 are not included in this projection due to a lack of future simulations. The two indices, cold nights (Tnn) and hot days (Txx), are chosen to illustrate the seasonal differences of changes at the extremes of both ends of the distribution of daily surface air temperatures. The upper left panel shows that the wintertime increase in cold nights has large changes northward of the middle of the US largely corresponding to present day winter snow covered areas. Kodra et al. (2011) studied cold extremes in the twentyfirst century using nine GCMs and found that despite future warming, extreme cold events, both in terms of intensity and duration, can persist in the future. Cool nights in the summer, shown in the upper right panel, do not exhibit such a monotonic poleward behavior. Rather, the continental interior warms more than the edges for this measure of extreme temperature. Wintertime increases in warm days, shown in the lower left panel, are projected to be significantly less than wintertime cold nights; although some of the poleward gradient property is present. Summertime increases in hot days are projected slightly warmer than but generally similar to summertime increases in cool nights. One noticeable difference is that future extreme 
Fig. 12 Projected seasonal changes in North American extreme temperatures from the CMIP5 multi-model at the end of this century under the RCP8.5 forcing scenario. The reference period is 1985-2005 while the future period is 2080-2100. Winter changes are shown on the left while summer changes are shown on the right. The top figures represent changes in cold nights (Tnn) while the lower figures represent changes in hot days (Txx). Units: Kelvins

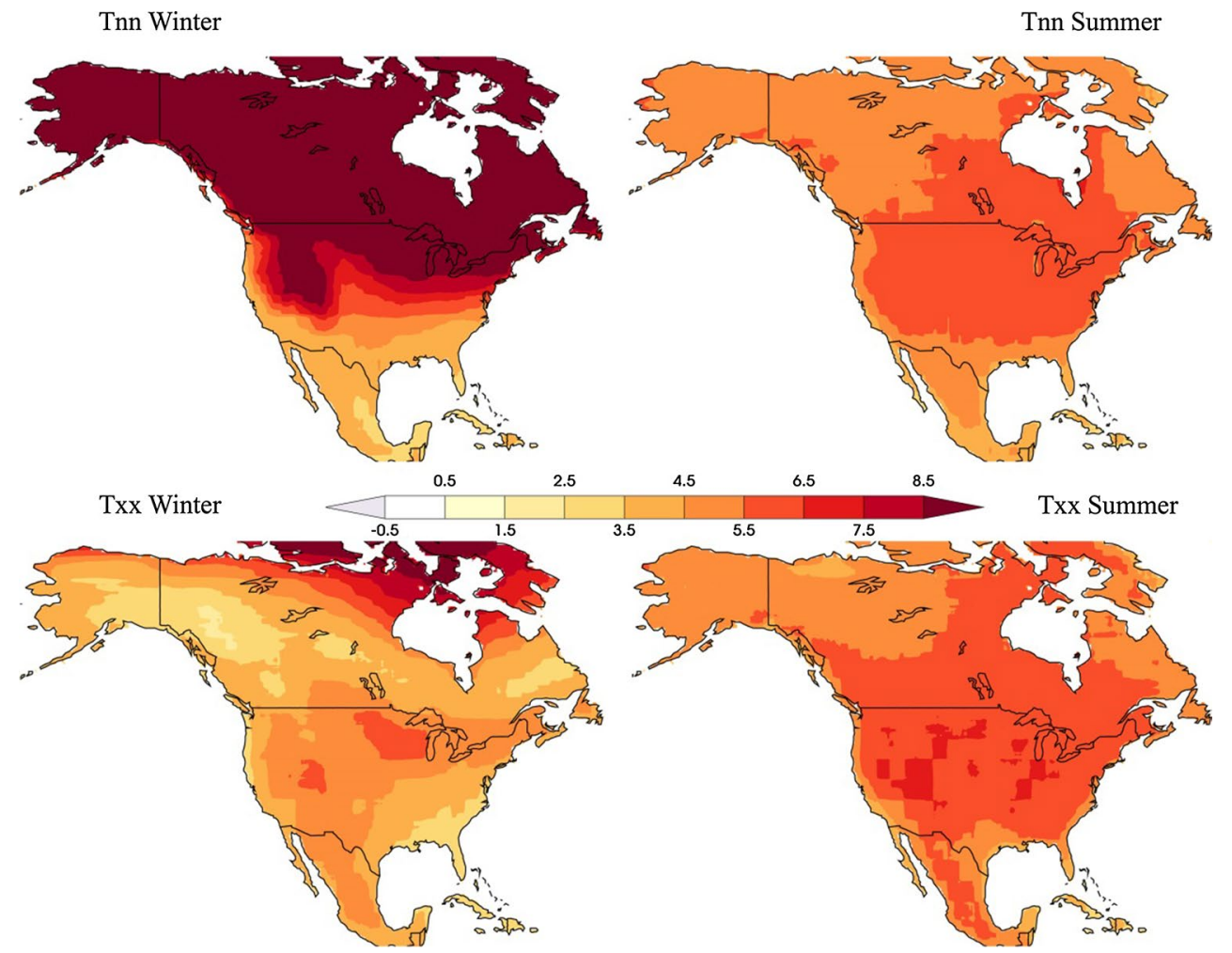

temperatures in the Mexican interior warm more in the summer than in the winter.

Seasonality in the projected changes of these two indices is a reflection of the complex mechanisms affecting changes in extreme and mean temperatures in North America. Changes in snow cover certainly affect the future winter mean and extreme temperatures. Likewise, decreases in soil moisture affect the future summer mean and extreme temperatures. The additional possibility of biases and changes in LSMPs affecting extreme temperatures must be considered in light of these and other mechanisms. For example, van Oldenborgh et al. (2009) found that changes in the large-scale circulation, including a shift towards a more westerly circulation and the North Atlantic current need to be better simulated especially in winter and spring for more realistic simulations of warming over Western Europe in recent decades. Gershunov and Guirguis (2012) noted that three out of four GCMs analyzed did not adequately capture the synoptic causes of California heat waves. When sub-regional heat waves are defined relative to the changing local climate (a 'non-stationary' perspective), coastal heat waves have greater impact than those inland even though the summertime average warming is stronger inland. Sillmann and Croci-Maspoli (2009) found that European blocking events influence particularly the winter cold extremes in Europe. For future projection, decrease in blocking frequency with increase in maximum blocking duration was simulated under the A1B scenario.
Also, the blocking pattern shifts northeastward, affecting a larger part of Europe by giving rise to anomalously cold winter months.

To partly address the question of whether changes in heat waves in the future are associated with a shift in the daily maximum temperature or changes in LSMP, Lau and Nath (2012) noted that the probability distribution functions (PDFs) for the current and future climate over most regions that experience heat waves in the US have similar shape but were shifted by the mean warming in the daily maximum temperature, and the magnitude of skewness of the PDFs exhibited only minor changes from the current to future climate. Further statistical manipulations of the model outputs suggest that the increase in heat wave intensity and frequency in the future is primarily associated with a shift in the daily maximum surface temperature, which suggests that changes in the characteristics of LSMPs associated with heat waves may be minor. Grotjahn (2015) shows trends in an LSMP index for California hot spells in reanalysis and both historical and future simulations by a climate model. Future changes in heat waves may also be modulated by changes in land-atmosphere interactions. For example, global warming may shift the climate regime northward and establish new transitional zones with strong land-atmosphere coupling strength (Seneviratne et al. 2006) and drying over the subtropics and mid-latitudes during summer in the future may increase land-atmosphere feedbacks in general (Dirmeyer et al. 2012) and 
result in amplified heat wave response to global warming. For CAOs, Schneider et al. (2015) and Gao et al. (2015) both demonstrated that the mean warming and the reduced temperature variance due to polar amplification account for most of the decrease in CAOs in a warmer climate. Gao et al. (2015) further found that changes in temperature skewness associated with changes in blocking frequency and thermodynamical modulation by melting of snow and sea ice along the $0{ }^{\circ} \mathrm{C}$ isotherm contribute additionally to regional differences in $\mathrm{CAO}$ changes.

Regional climate models have also been used to investigate temperature extreme changes in the future. Kunkel et al. (2010) showed that the regional model has superior skill in simulating heat waves compared to the global models, but it largely inherited the climate sensitivity from the GCMs. They found considerable regional variations in future heat wave characteristics depending on the emission scenarios and GCMs used. Using a suite of regional climate simulations driven by 5 ensemble members of a GCM, Diffenbaugh and Ashfaq (2010) found that hot extremes are intensified over much of the US associated with a summer anticyclonic circulation anomaly in the future, which reduces precipitation and soil moisture, and amplifies severe hot and dry conditions. The regional simulations showed a summer anticyclonic anomaly that is more widespread than in the GCM.

Overall, some robust changes in temperature extremes have emerged from analysis of the CMIP3 and CMIP5 multimodel ensembles as well as targeted global and regional climate modeling efforts. Model projections generally indicate increased frequency, intensity, and duration of heat waves, and despite global warming, cold extremes may persist in some regions due to changes in blocking events (Vavrus et al. 2006; Gao et al. 2015). More detailed analyses using multimodel ensembles may provide further insights on the mechanisms of heat wave changes associated with land-atmosphere coupling and potential changes in LSMPs affecting both heat waves and cold air outbreaks. Additionally, well-designed climate modeling experiments combined with observational analyses that target specific mechanisms and hypotheses may help isolate different factors and provide constraints for more robust projections of temperature extreme changes.

\section{Summary}

This review paper summarizes our current knowledge of, and context for developing new understandings about, extreme hot and cold temperature events affecting regions of North America. The topic of extremes encompasses many scientific issues and a breadth of time and space scales. Understanding extreme events ranges from how events are defined and measured, to how extreme events are studied statistically, theoretically, and with models. To reduce the breadth of scales, the paper focuses upon the large scale meteorological patterns (LSMPs) that accompany extreme temperature events (ETEs) of short duration. However, even with this narrower focus, one easily sees that much further progress is needed to understand the properties of extreme temperature events and their supporting LSMP processes. Thus, the primary goal of this report is to provide guidance to researchers interested in studying extreme temperature events, especially in relation to their associated LSMPs. As such, a variety of techniques are described for identifying the LSMPs, including the relative merits of each approach. A variety of analysis tools are identified which highlight the linkage of LSMPs to both remote low frequency phenomena and local factors. Also highlighted is the information gleaned from multiple climate models including simulation issues and projected trends.

Section 2 presents methods of defining extreme temperature events statistics using both simple indices and extreme value statistical techniques. Also surveyed are methods used to identify and connect LSMPs to extreme temperatures. Recent advances in statistical techniques, involving conditional extreme value analysis, offer an opportunity to connect LSMPs to extreme temperatures through appropriately defined covariates (i.e., indices of LSMPs) that supplement more straightforward analyses.

Section 3 surveys our current knowledge of LSMPs related to ETEs. Although phenomena ranging from synoptic-scale waves to planetary-scale climate modes are implicated as contributors to ETEs, existing information on (a) the physical nature of these contributions and (b) the dynamical mechanisms responsible for the implicated LSMPs is uneven and incomplete. A diagnostic formalism is put forth for systematically isolating the underlying physics of LSMP life cycles with an ancillary goal of identifying essential large-scale circulation "markers" for climate model validation purposes.

Section 4 summarizes the approaches used to model extreme temperatures, including dynamical methods using global and regional climate models and statistical models. Although climate models generally capture heat waves and cold air outbreaks with some fidelity compared with observations, they overestimate warm wave frequency and underestimate CAO frequency. Furthermore, while CMIP5 models properly represent many of the significant associations between ETEs and low frequency modes, they underestimate the collective influence of low-frequency modes on temperature extremes, particularly related to the Pacific Decadal Oscillation. Statistical methods used to relate LSMPs with extremes are limited mainly by small sample sizes of extreme events, so that only a small number 
of predictors can be included to ensure robust statistical relationships.

Section 5 surveys observed and projected trends in extreme temperatures. The studies that form the basis of the IPCC AR5 reports and the 3rd US National Climate Assessment do not consider the role of LSMPs in the magnitude and trends of extreme temperatures. However, a survey of the limited literature exploring these roles in North America and Europe suggests that future assessments, particularly at the regional scale, must include the connection between LSMPs and extreme temperature events.

In preparing this report it became apparent that much work remains to understand better past and future occurrences of ETEs and their underlying physical causes. Below are key questions relating to LSMPs that may guide future research.

Data and statistical methods Can statistical significance tests be developed for all LSMP detection methods? What are the effects of spatial resolution and gridding of station data on extreme value temperature analysis? How shall multivariate extreme statistical tools be optimally employed? What extreme values are most useful to various application sectors? Can the uncertainty be quantified in statistical quantities for given lengths of the observational or model data?

Synoptic behavior and physical mechanisms What physical/dynamical mechanisms form and maintain these rare LSMPs? Is more than one type of LSMP pattern responsible for a given regional ETE? Do specific LSMPs arise by different processes? (e.g. Lee and Grotjahn 2015) Can one quantify the extent to which low frequency phenomena such as blocking, MJO and ENSO contribute to each ETE? (e.g. Dole et al. 2014) Can one quantify the relative contributions of local factors such as topography, land surface states, and land use/land cover in ETE duration and severity? How do LSMPs vary with season and regional location? How sensitive is LSMP characterization to how the associated ETE is defined?

Model behavior and trends How well do global and regional climate models simulate the synoptic-dynamic behavior of relevant LSMPs and their variability and trends compared to observations/reanalyses? Can deficiencies in model dynamics or physical parameterizations be linked to model deficiencies in LSMP properties? How well must LSMP properties be simulated by global climate models to provide sufficiently accurate lateral boundary conditions for regional climate models to accurately simulate the associated ETE? Can metrics be designed to discern and understand differences in model skill in simulating an ETE and the associated LSMP?

Future properties What are the relative roles of dynamical and thermodynamical changes to future changes in LSMPs associated with ETEs? Considering current limitations of climate models, how can one optimally assess the uncertainty in model projections of future changes in relevant LSMPs and their ETEs? Beyond ensemble modeling, what type of coordinated experiments can be performed to systematically evaluate models and infer the sources of model differences in LSMPs and ETEs? How can such model evaluations improve our interpretation of model projections of future changes in extremes and LSMPs?

While many gaps exist, investigators now have a large variety of tools and a useful LSMP framework by which to pursue better understanding of both historical and future extreme temperature events.

Acknowledgments The authors thank Dr. Christopher J. Paciorek for his assistance in preparing this article. The authors also thank Dr. Steven Vavrus for his comments. Most of the authors are members of the US CLIVAR Extremes working group who greatly appreciate the support provided by the US CLIVAR office. This report was enhanced by discussions held at the 2013 workshop on Analyses, Dynamics, and Modeling of Large Scale Meteorological Patterns Associated with Extreme Temperature and Precipitation Events held at the Lawrence Berkeley National Laboratory and also funded by US CLIVAR (https://usclivar.org/meetings/extremes-workshop-agenda). Research by Grotjahn was funded in part by NSF Grant 1236681 and also supported by the USDA National Institute of Food and Agriculture, Hatch project CA-D-LAW-4264-H. Leung and Wehner were supported by the Regional and Global Climate Modeling Program of the Office of Biological and Environmental Research in the Department of Energy Office of Science. Pacific Northwest National Laboratory is operated by Battelle Memorial Institute for the DOE under contract DE-AC05-76RL01830 and Lawrence Berkeley National Laboratory is under contract DE-AC02-05CH11231. Black was supported by the US Department of Energy, Office of Biological and Environmental Research, awards DE-SC0004942 and DE-SC0012554, and the National Science Foundation Grant ARC-1107384. Gutowski was supported by National Science Foundation Grant ARC1023369 and Department of Energy Grant DESC0006643. Gyakum was supported by a Natural Sciences and Engineering Research Council of Canada Discovery Grant, and by an International Polar Year Grant. The National Center for Atmospheric Research is sponsored by the National Science Foundation.

Open Access This article is distributed under the terms of the Creative Commons Attribution 4.0 International License (http://creativecommons.org/licenses/by/4.0/), which permits unrestricted use, distribution, and reproduction in any medium, provided you give appropriate credit to the original author(s) and the source, provide a link to the Creative Commons license, and indicate if changes were made.

\section{References}

Alexander LV, Zhang X, Peterson TC, Caesar J, Gleason B, Klein Tank AMG, Haylock M, Collins D, Trewin B, Rahimzadeh F, Tagipour A, Rupa Kumar K, Revadekar J, Griffiths G, Vincent L, Stephenson DB, Burn J, Aguilar E, Brunet M, Taylor M, New M, Zhai P, Rusticucci M, Vazquez-Aguirre JL (2006) Global observed changes in daily climate extremes of temperature and precipitation. J Geophys Res 111:D05109. doi:10.1029/2005JD006290

Alexander L, Uotila P, Nicholls N (2009) Influence of sea surface temperature variability on global temperature and precipitation extremes. J Geophys Res 114:D18116 
Bachmann B (2008) The spatial extent of California heat waves. MS Thesis, Atmospheric Science Program, University of California Davis. March. 164 pp. http://grotjahn.ucdavis.edu/EWEs/

Barnes EA (2013) Revisiting the evidence linking Arctic amplification to extreme weather in midlatitudes. Geophys Res Lett 40:4734-4739. doi:10.1002/grl.50880

Beniston M (2004) The 2003 heat wave in Europe: a shape of things to come? An analysis based on Swiss climatological data and model simulations. Geophys Res Lett 31:L02202. doi:10.1029 /2003GL018857

Black RX, Evans KJ (1998) The statistics and horizontal structure of anomalous weather regimes in the community climate model. Mon Weather Rev 126(4):841-859

Bosilovich MG (2013) Regional climate and variability of NASA MERRA and recent reanalyses: US summertime precipitation and temperature. J Appl Meteorol Climatol 52:1939-1951. doi:10.1175/JAMC-D-12-0291.1

Brewer MC, Mass CF, Potter BE (2012) The west coast thermal trough: climatology and synoptic evolution. Mon Weather Rev 140:3820-3843. doi:10.1175/MWR-D-12-00078.1

Brown S, Caesar J, Ferro C (2008) Global changes in extreme daily temperature since 1950. J Geophys Res 113:D05115. doi:10.10 29/2006JD008091

Bumbaco KA, Dello KD, Bond NA (2013) History of Pacific Northwest heat waves: synoptic pattern and trends. J Appl Meteorol Climatol 52:1618-1631. doi:10.1175/JAMC-D-12-094.1

Carrera M, Higgins R, Kousky V (2004) Downstream weather impacts associated with atmospheric blocking over the Northeast Pacific. J Clim 17:4823-4839

Cassano EN, Lynch AH, Cassano JJ, Koslow MR (2006) Classification of synoptic patterns in the western Arctic associated with extreme events at Barrow, Alaska. Clim Res 30:83-97

Cassano JJ, Uotila P, Lynch AH, Cassano EN (2007) Predicted changes in synoptic forcing of net precipitation in large Arctic river basins during the 21st century. J Geophys Res 112:G04S49. doi:10.1029/2006JG000332

Cavazos T (2000) Using self-organizing maps to investigate extreme climate events: an application to wintertime precipitation in the Balkans. J Clim 13:1718-1732

Cellitti M, Walsh J, Rauber R, Portis D (2006) Extreme cold air outbreaks over the United States, the polar vortex, and the largescale circulation. J Geophys Res 111:D02114. doi:10.1029/20 05JD006273

Chang F-C, Wallace JM (1987) Meteorological conditions during heat waves and droughts in the United States great plains. Mon Weather Rev 115:1253-1269

Chen F, Konrad CE II (2006) A synoptic climatology of summertime heat and humidity in the piedmont region of North Carolina. J Appl Meteorol Climatol 45(5):674-685

Christidis N, Stott PA, Brown S, Hegerl GC, Caesar J (2005) Detection of changes in temperature extremes during the second half of the 20th century. Geophys Res Lett 32:L20716. doi:10.1029 /2005GL023885

Cohen J, Jones J (2011) A new index for more accurate winter predictions. Geophys Res Lett 38:L21701. doi:10.1029/201 $1 \mathrm{GL} 049626$

Cohen J, Barlow M, Kushner P, Saito K (2007) Stratosphere-troposphere coupling and links with Eurasian land-surface variability. J Clim 20:5335-5343. doi:10.1175/2007JCLI1725.1

Cohen J, Jones J, Furtado JC, Tziperman E (2013) Warm Arctic, cold continents: a common pattern related to Arctic sea ice melt, snow advance, and extreme winter weather. Oceanography. doi:10.5670/oceanog.2013.70

Cohen J, Screen JA, Furtado JC, Barlow M, Whittleston D, Coumou D, Francis J, Dethloff K, Entekhabi D, Overland J, Jones
J (2014) Recent Arctic amplification and extreme mid-latitude weather. Nat Geosci 7:627-637. doi:10.1038/ngeo2234

Coles S (2001) An introduction to statistical modeling of extreme values. Springer, London

Colle BA, Mass CF (1995) The structure and evolution of cold surges east of the Rocky Mountains. Mon Weather Rev 123:2577-2610. doi:10.1175/1520-0493(1995)123<2577:TSAEOC >2.0.CO;2

Compo GP, Whitaker JS, Sardeshmukh PD (2006) Feasibility of a 100 year reanalysis using only surface pressure data. Bull Am Meteorol Soc 87:175-190

Compo GP, Whitaker JS, Sardeshmukh PD, Matsui N, Allan RJ, Yin X, Gleason BE, Vose RS, Rutledge G, Bessemoulin P, Brönnimann S, Brunet M, Crouthamel RI, Grant AN, Groisman PY, Jones PD, Kruk MC, Kruger AC, Marshall GJ, Maugeri M, Mok HY, Nordli $\varnothing$, Ross TF, Trigo RM, Wang XL, Woodruff SD, Worley SJ (2011) The twentieth century reanalysis project. Q J R Meteorol Soc 137:1-28. doi:10.1002/qj.776

Curry J (1983) On the formation of continental polar air. J Atmos Sci 40:2278-2292

Dee DP, Uppala SM, Simmons AJ, Berrisford P, Poli P, Kobayashi S, Andrae U, Balmaseda MA, Balsamo G, Bauer P, Bechtold P, Beljaars ACM, van de Berg L, Bidlot J, Bormann N, Delsol C, Dragani R, Fuentes M, Geer AJ, Haimberger L, Healy SB, Hersbach H, Hólm EV, Isaksen L, Kållberg P, Köhler M, Matricardi M, McNally AP, Monge-Sanz BM, Morcrette J-J, Park B-K, Peubey C, de Rosnay P, Tavolato C, Thépaut J-N, Vitart F (2011) The ERA-Interim reanalysis: configuration and performance of the data assimilation system. Q J R Meteorol Soc 137:553-597

Diffenbaugh NS, Ashfaq M (2010) Intensification of hot extremes in the United States. Geophys Res Lett. doi:10.1029/201 0GL043888

Dirmeyer PA, Cash BA, Kinter JL III, Stan C, Jung T, Marx L, Towers P, Wedi N, Adams JM, Altshuler EL, Huang B, Jin EK, Manganello J (2012) Evidence for enhanced land-atmosphere feedback in a warming climate. J Hydrometeorol 13(3):981-995

Dole R, Hoerling M, Kumar A, Eischeid J, Perlwitz J, Quan X-W, Kiladis G, Webb R, Murray D, Chen M, Wolter K, Zhang $\mathrm{T}$ (2014) The making of an extreme event: putting the pieces together. Bull Am Meteorol Soc 95:427-440. doi:10.1175/ BAMS-D-12-00069.1

Downton M, Miller K (1993) The freeze risk to Florida citrus. Part II: temperature variability and circulation patterns. J Clim 6:364-372

Easterling D (1999) Development of regional climate scenarios using a downscaling approach. Clim Change 41:615-634

Emanuel K (2009) Back to Norway: an essay. Synoptic-dynamic meteorology and weather analysis forecasting. Meteorol Monogr 55, Am Meteorol Soc 87-96

Evans KJ, Black RX (2003) Piecewise tendency diagnosis of weather regime transitions. J Atmos Sci 60:1941-1959

Favre A, Gershunov A (2006) Extra-tropical cyclonic/anticyclonic activity in North-Eastern Pacific and air temperature extremes in Western North America. Clim Dyn 26:617-629. doi:10.1007/ s00382-005-0101-9

Fawcett L, Walshaw D (2012) Estimating return levels from serially dependent extremes. Environmetrics 23:272-283

Feldstein SB (2000) Teleconnections and ENSO: the timescale, power spectra, and climate noise properties. J Clim 13:4430-4440

Feldstein SB (2002) Fundamental mechanisms of PNA teleconnection pattern growth and decay. Q J R Meteorol Soc 128:775-796

Feldstein SB (2003) The dynamics of NAO teleconnection pattern growth and decay. Q J R Meteorol Soc 129:901-924

Fischer EM, Seneviratne SI, Lüthi D, Schär C (2007) Contribution of land-atmosphere coupling to recent European summer 
heat waves. Geophys Res Lett 34:L06707. doi:10.1029/200 6GL029068

Forbes GS, Anthes RA, Thomson DW (1987) Synoptic and mesoscale aspects of an Appalachian ice storm associated with cold-air damming. Mon Weather Rev 115:564-591

Francis JA, Vavrus SJ (2012) Evidence linking Arctic amplification to extreme weather in mid-latitudes. Geophys Res Lett. doi:10.10 29/2012GL051000

Francis JA, Chan W, Leathers DJ, Miller JR, Veron DE (2009) Winter northern hemisphere weather patterns remember summer Arctic sea-ice extent. Geophys Res Lett 36:L07505. doi:10.1029/200 9GL037274

Franzke C, Feldstein SB, Lee S (2011) Synoptic analysis of the Pacific-North American teleconnection pattern. Q J R Meteorol Soc 137:329-346. doi:10.1002/qj.768

Fritsch JM, Kapolka J, Hirschberg PA (1992) The effects of subcloudlayer diabatic processes on cold air damming. J Atmos Sci 49:49-70

Furrer EM, Katz RW, Walter MD, Furrer R (2010) Statistical modeling of hot spells and heat waves. Clim Res 43:191-205

Gao Y, Fu JS, Drake JB, Liu Y, Lamarque J-F (2012) Projected changes of extreme weather events in the eastern United States based on a high resolution climate modeling system. Environ Res Lett. doi:10.1088/1748-9326/7/4/044025

Gao Y, Leung LR, Lu J, Masato G (2015) Persistent cold air outbreaks over North America in a warming climate. Environ Res Lett. doi:10.1088/1748-9326/10/4/044001

Gershunov A, Douville H (2008) Extensive summer hot and cold extremes under current and possible future climatic conditions: Europe and North America. In: Diaz HF, Murnane RJ (eds) Climate extremes and society. Cambridge University Press, New York, pp 74-98

Gershunov A, Guirguis K (2012) California heat waves in the present and future. Geophys Res Lett 39:L18710. doi:10.1029/20 12GL052979

Gershunov A, Cayan DR, Iacobellis SF (2009) The great 2006 heat wave over California and Nevada: signal of an increasing trend. J Clim 22:6181-6203

Gleason KL, Lawrimore JH, Levinson DH, Karl TR, Karoly DJ (2008) A revised US climate extremes index. J Clim 21:21242137. doi:10.1175/2007JCLI1883.1

Gleckler PJ, Taylor KE, Doutriaux C (2008) Performance metrics for climate models. J Geophys Res 113:D06104. doi:10.1029/200 7JD008972

Gosling SN, McGregor GR, Paldy A (2007) Climate change and heatrelated mortality in six cities Part 1: model construction and validation. Int J Biometeorol 51:525-540

Gotaas Y, Benson CS (1965) The effect of suspended ice crystals on radiative cooling. J Appl Meteorol 4:446-453

Goto-Maeda Y, Shin D, O'Brien J (2008) Freeze probability of Florida in a regional climate model and climate indices. Geophys Res Lett 35:L11703. doi:10.1029/2008GL033720

Grotjahn R (2011) Identifying extreme hottest days from large scale upper air data: a pilot scheme to find California central valley summertime maximum surface temperatures. Clim Dyn 37:587-604. doi:10.1007/s00382-011-0999-z

Grotjahn R (2013) Ability of CCSM4 to simulate California extreme heat conditions from evaluating simulations of the associated large scale upper air pattern. Clim Dyn 41:1187-1197. doi:10.1007/s00382-013-1668-1

Grotjahn R (2015) Western North American extreme heat, associated large scale synoptic-dynamics, and performance by a climate model. In: Li J, Swinbank R, Volkert H, Grotjahn R (eds) Dynamics and predictability of large-scale, high-impact weather and climate events. Cambridge University Press, Cambridge
Grotjahn R, Faure G (2008) Composite predictor maps of extraordinary weather events in the Sacramento California region. Weather Forecast 23:313-335. doi:10.1175/2007 WAF2006055.1

Gu L, Hanson P, Post W, Kaiser D, Yang B, Nemani R, Pallardy S, Meyers T (2008) The 2007 eastern US spring freezes: increased cold damage in a warming world? Bioscience 58:253-262

Guirguis K, Gershunov A, Schwartz R, Bennett S (2011) Recent warm and cold daily winter temperature extremes in the Northern Hemisphere. Geophys Res Lett 38:L17701. doi:10.1029/20 11GL048762

Gutowski WJ, Otieno F, Arritt RW, Takle ES, Pan Z (2004) Diagnosis and attribution of a seasonal precipitation deficit in a US regional climate simulation. J Hydrometeorol 5:230-242. doi:10.1175/1525-7541(2004)005<0230:DAAOAS >2.0.CO;2

Hajat S, Kovats RS, Atkinson RW, Haines A (2002) Impact of hot temperatures on death in London: a time series approach. J Epidemiol Community Health 56:367-372

Hewitson BC, Crane RG (2002) Self-organizing maps: applications to synoptic climatology. Clim Res 18:41-57

Hewitson BC, Crane RG (2006) Consensus between GCM climate change projections with empirical downscaling: precipitation downscaling over South Africa. Int J Climatol 26:1315-1337. doi:10.1002/joc. 1314

Higgins R, Leetmaa A, Kousky V (2002) Relationships between climate variability and winter temperature extremes in the United States. J Clim 15:1555-1572

Hinton G, Deng L, Yu D, Dahl G, Mohamed A-R, Jaitly N, Senior A, Vanhoucke V, Nguyen P, Sainath T, Kingsbury B (2012) Deep neural networks for acoustic modeling in speech recognition: the shared views of four research groups. Sig Process Mag IEEE 29(6):82-97

Ho CK, Stephenson DB, Collins M, Ferro CAT, Brown SJ (2012) Calibration strategies: a source of additional uncertainty in climate change projections. Bull Am Meteorol Soc 93:21-26

Hohenegger C, Schär C (2007) Atmospheric predictability at synoptic versus cloud-resolving scales. Bull Am Meteorol Soc 88:1783-1793

Jaeger EB, Seneviratne SI (2011) Impact of soil moisture-atmosphere coupling on European climate extremes and trends in a regional climate model. Clim Dyn 36(9-10):1919-1939. doi:10.1007/ s00382-010-0780-8

Jaiser R, Dethloff K, Handorf D, Rinke A, Cohen J (2012) Impact of sea ice cover changes on the northern hemisphere atmospheric winter circulation. Tellus A 64:11595. doi:10.3402/tellusa. v64i0.11595

Kallache M, Vrac M, Naveau P, Michelangeli P-A (2011) Nonstationary probabilistic downscaling of extreme precipitation. J Geophys Res 116:D05113. doi:10.1029/2010JD014892

Karl TR, Quayle RG (1981) The 1980 summer heat wave and drought in historical perspective. Mon Weather Rev 109:2055-2073. doi:10.1175/1520-0493(1981)109<2055:TSHWAD>2.0.CO;2

Karl TR, Knight RW, Easterling DR, Quayle RG (1996) Indices of climate change for the United States. Bull Am Meteorol Soc 77:279-292. doi:10.1175/1520-0477(1996)077<0279:IOCCFT $>2.0 . \mathrm{CO} ; 2$

Katz RW (2010) Statistics of extremes in climate change. Clim Change 100:71-76

Katz RW, Grotjahn R (2014) Statistical methods for relating temperature extremes to large-scale meteorological patterns. US CLIVAR Var 12(1):4-7. http://www.usclivar.org/sites/default/files/ documents/2014/Variations-winter-2014-v3.pdf

Kenyon J, Hegerl G (2008) Influence of modes of climate variability on global temperature extremes. J Clim 21:3872-3889. doi:10.1 175/2008JCLI2125.1 
Kharin VV, Zwiers FW, Zhang X, Wehner M (2013) Changes in temperature and precipitation extremes in the CMIP5 ensemble. Clim Change 119:345-347

Klein W (1952) The weather and circulation of June 1952. Mon Weather Rev 80:99-104

Kodra E, Steinhaeuser K, Ganguly AR (2011) Persisting cold extremes under 21st-century warming scenarios. Geophys Res Lett 38:L08705. doi:10.1029/2011GL047103

Kohonen T (1995) Self-organizing maps, 2nd edn. Springer, Berlin

Konrad C II (1996) Relationships between the intensity of cold-air outbreaks and the evolution of synoptic and planetary-scale features over north America. Mon Weather Rev 124:1067-1083. doi:10.1175/1520-0493(1996)124<1067:RBTIOC >2.0.CO;2

Konrad CE II, Colucci SJ (1989) An examination of extreme cold air outbreaks over eastern North America. Mon Weather Rev 117:2687-2700

Krizhevsky A, Sutskever I, Hinton G (2012) Imagenet classification with deep convolutional neural networks. In: Advances in neural information processing systems 25 (proceedings from NIPS 2012). http://papers.nips.cc/paper/4824-imagenet-classificationwith-deep-convolutional-neural-networks.pdf

Kunkel KE, Changnon SA, Reinke BC, Arritt RW (1996) The July 1995 heat wave in the Midwest: a climatic perspective and critical weather factors. Bull Am Meteorol Soc 77:1507-1518

Kunkel KE, Liang X-Z, Zhu J (2010) Regional climate model projections and uncertainties of US Summer heat waves. J Clim 23:4447-4458

Lau N-C, Nath MJ (2012) A model study of heat waves over North America: meteorological aspects and projections for the twenty-first century. J Clim 25:4761-4784. doi:10.1175/ JCLI-D-11-00575.1

Lee Y-Y, Black RX (2013) Boreal winter low-frequency variability in CMIP5 models. J Geophys Res Atmos 118:6891-6904. doi:10.1002/jgrd.50493

Lee Y-Y, Grotjahn R (2015) California Central Valley summer heat waves form two ways. J Clim (under review)

Leibensperger EM, Mickley LJ, Jacob DJ, Chen W-T, Seinfeld JH, Nenes A, Adams PJ, Streets DG, Kumar N, Rind D (2012) Climatic effects of 1950-2050 changes in US anthropogenic aerosols_-Part 2: climate response. Atmos Chem Phys 12:33493362. doi:10.5194/acp-12-3349-2012

Lim YK, Kim HD (2013) Impact of the dominant large-scale teleconnections on winter temperature variability over East Asia. J Geophys Res 118:7835-7848. doi:10.1002/jgrd.50462

Lim Y-K, Schubert S (2011) The impact of ENSO and the Arctic Oscillation on winter temperature extremes in the southeast United States. Geophys Res Lett 38:L15706. doi:10.1029/201 1GL048283

Lim YK, Ham YG, Jeong JH, Kug JS (2012) Improvement in simulation of Eurasian winter climate variability with a realistic Arctic sea ice condition in an atmospheric GCM. Environ Res Lett 7:044041. doi:10.1088/1748-9326/7/4/044041

Lipton K, Grumm R, Holmes R (2005) Forecasting heat waves using climatic anomalies. In: 21st conference on weather analysis/17th conference on numerical weather prediciton. 1-5 August 2005. http://ams.confex.com/ams/pdfpapers/94498.pdf

Liu J, Curry JA, Wang H, Song M, Horton RM (2012) Impact of declining Arctic sea ice on winter snowfall PNAS. Proc Natl Acad Sci 109:4074-4079. doi:10.1073/pnas.1114910109

Livezey RE, Tinker R (1996) Some meteorological, climatological, and microclimatological considerations of the severe US heat wave of mid-July 1995. Bull Am Meteorol Soc 77:2043-2054

Loikith P, Broccoli A (2012) Characteristics of observed atmospheric circulation patterns associated with temperature extremes over North America. J Clim 25:7266-7281. doi:10.1175/ JCLI-D-11-00709.1
Loikith PC, Broccoli AJ (2014) The influence of recurrent modes of climate variability on the occurrence of winter and summer extreme temperatures over North America. J Clim 27:1600-1618

Lorenz R, Jaeger EB, Seneviratne SI (2010) Persistence of heat waves and its link to soil moisture memory. Geophys Res Lett 37:L09703. doi:10.1029/2010GL042764

Lyon B (2009) Southern Africa summer drought and heat waves: observations and coupled model behavior. J Clim 22:60336046. doi:10.1175/2009JCLI3101.1

Lyon B, Dole RM (1995) A diagnostic comparison of the 1980 and 1988 US summer heat wave-droughts. J Clim 8:1658-1675

Maraun D (2013) Bias correction, quantile mapping, and downscaling: revisiting the inflation issue. J Clim 26:2137-2143

Masato G, Hoskins BJ, Woollings T (2013) Winter and summer northern hemisphere blocking in CMIP5 models. J Clim 26:7044-7059

Meehl G, Tebaldi C (2004) More intense, more frequent, and longer lasting heat waves in the twenty-first century. Science 305:994-997

Meehl G, Tebaldi C, Teng H, Peterson T (2007) Current and future US weather extremes and El Niño. Geophys Res Lett 34:L20704. doi:10.1029/2007GL031027

Moon J-Y, Wang B, Ha K (2011) ENSO regulation of MJO teleconnection. Clim Dyn 37:1133-1149

Moss RH, Edmonds JA, Hibbard KA, Manning MR, Rose SK, van Vuuren DP, Carter TR, Emori S, Kainuma M, Kram T, Meehl GA, Mitchell JFB, Nakicenovic N, Riahi K, Smith SJ, Stouffer RJ, Thomson AM, Weyant JP, Wilbanks TJ (2010) The next generation of scenarios for climate change research and assessment. Nature 463:747-756. doi:10.1038/nature08823

Nakicenovic N, Alcamo J, Davis G, de Vries HJM, Fenhann J, Gaffin S, Gregory K, Grubler A, Jung TY, Kram T, La Rovere EL, Michaelis L, Mori S, Morita T, Papper W, Pitcher H, Price L, Riahi K, Roehrl A, Rogner H-H, Sankovski A, Schlesinger M, Shukla P, Smith S, Swart R, van Rooijen S, Victor N, Dadi Z (2000) Special report on emissions scenarios. Intergovernmental Panel on Climate Change, Cambridge University Press, Cambridge

Namias J (1982) Anatomy of great plains protracted heat waves (especially the 1980 US summer drought). Mon Weather Rev 110:824-838

Orlowsky B, Seneviratne SI (2012) Global changes in extreme events: regional and seasonal dimension. Clim Change 110:669-696. doi:10.1007/s10584-011-0122-9

Outten SD, Esau I (2012) A link between Arctic sea ice and recent cooling trends over Eurasia. Clim Change 110:1069-1075. doi:10.1007/s10584-011-0334-z

Overland JE, Wang M (2010) Large-scale atmospheric circulation changes associated with the recent loss of Arctic sea ice. Tellus A 62:1-9. doi:10.1111/j.1600-0870.2009.00421.x

Palecki MA, Changnon SA, Kunkel KE (2001) The nature and impacts of the July 1999 heat wave in the midwestern United States: learning from the lessons of 1995. Bull Am Meteorol Soc 82:1353-1367

Park T-W, Ho C-H, Yang S (2011) Relationship between the Arctic Oscillation and cold surges over East Asia. J Clim 24:68-83

Peings Y, Brun E, Mauvais V, Douville H (2013) How stationary is the relationship between Siberian snow and Arctic Oscillation over the 20th century? Geophys Res Lett 40:183-188. doi:10.1029/2 012GL054083

Peterson TC, Heim R, Hirsch R, Kaiser D, Brooks H, Diffenbaugh NS, Dole R, Giovannettone J, Guiguis K, Karl TR, Katz RW, Kunkel K, Lettenmaier D, McCabe GJ, Paciorek CJ, Ryberg K, Schubert S, Silva VBS, Stewart B, Vecchia AV, Villarini G, Vose RS, Walsh J, Wehner M, Wolock D, Wolter K, Woodhouse 
CA, Wuebbles D (2013) Monitoring and understanding changes in heat waves, cold waves, floods and droughts in the United States: state of knowledge. Bull Am Meteorol Soc 94:821-834. doi:10.1175/BAMS-D-12-00066.1, Supplement doi:10.1175/ BAMS-D-12-00066.2

Photiadou C, Jones MR, Keelings D, Dewes CF (2014) Modelling European hot spells using extreme value analysis. Clim Res 58:193-207. doi:10.3354/cr01191

Plumb RA (1985) On the three-dimensional propagation of stationary waves. J Atmos Sci 42:217-229

Portis DH, Cellitti MP, Chapman WL, Walsh JE (2006) Low-frequency variability and evolution of north american cold air outbreaks. Mon Weather Rev 134:579-597

Renwick JA, Wallace JM (1996) Relationships between north Pacific wintertime blocking, El Niño, and the PNA pattern. Mon Weather Rev 124:2071-2076

Rienecker $M$ et al (2007) The GEOS-5 data assimilation systemdocumentation of versions 5.0.1 and 5.1.0. NASA GSFC technical report series on global modeling and data assimilation, NASA/TM-2007-104606, vol 27, 92 pp

Robinson P (2001) On the definition of a heat wave. J Appl Meteorol 40:762-775

Saha $S$ et al (2010) The NCEP climate forecast system reanalysis. Bull Am Meteorol Soc 91:1015-1057

Salakhutdinov R, Hinton G (2012) An efficient learning procedure for deep Boltzmann machines. Neural Comput 24(8):1967-2006

Sardeshmukh PD, Hoskins BJ (1988) The generation of global rotational flow by steady idealized tropical divergence. J Atmos Sci 45:1228-1251

Scaife AA, Woollings T, Knight J, Martin G, Hinton T (2010) Atmospheric blocking and mean biases in climate models. J Clim 23(23):6143-6152

Schneider T, Bischoff T, Plotka H (2015) Physics of changes in synoptic midlatitude temperature variability. J Clim 28:2312-2331

Schubert S, Wang H, Suarez M (2011) Warm season subseasonal variability and climate extremes in the Northern Hemisphere: the role of stationary Rossby waves. J Clim 24:4773-4792

Screen JA, Simmonds I (2013) Exploring links between Arctic amplification and midlatitude weather. Geophys Res Lett 40:959964. doi:10.1002/GRL.50174

Seber GAF (2008) Multivariate distributions, multivariate observations, Wiley, pp 17-58, ISBN 0-471-69121-6

Seneviratne SI, Luthi D, Litschi M, Schar C (2006) Land-atmosphere coupling and climate change in Europe. Nature 443:205-209. doi:10.1038/nature05095

Sillmann J, Croci-Maspoli M (2009) Present and future atmospheric blocking and its impact on European mean and extreme climate. Geophys Res Lett 36:L10702

Sillmann J, Croci-Maspoli M, Kallache M, Katz RW (2011) Extreme cold winter temperatures in europe under the influence of North Atlantic atmospheric blocking. J Clim 24:5899-5913. doi:10.11 75/2011JCLI4075.1

Sillmann J, Kharin VV, Zwiers FW, Zhang X, Bronaugh D (2013a) Climate extremes indices in the CMIP5 multi model ensemble: Part 1. Model evaluation in the present climate. J Geophys Res 118:1716-1733

Sillmann J, Kharin VV, Zwiers FW, Zhang X, Bronaugh D (2013b) Climate extremes indices in the CMIP5 multi model ensemble: Part 2. Future climate projections. J Geophys Res 118:2473-2493

Simmons AJ, Willett KM, Jones PD, Thorne PW, Dee DP (2010) Low-frequency variations in surface atmospheric humidity, temperature, and precipitation: inferences from reanalyses and monthly gridded observational data sets. J Geophys Res 115:D01110. doi:10.1029/2009JD012442
Smyth P, Ghil M, Ide K (1999) Multiple regimes in Northern Hemisphere height fields via mixture model clustering. J Atmos Sci 56:3704-3723

Spath H (1985) Cluster dissection and analysis: theory, FORTRAN programs, examples. Horwood, $226 \mathrm{pp}$

Stephanon M, D'Andrea F, Drobinski P (2012) Heatwave classification over Europe and the Mediterranean region. Environ Res Lett 7:014023. doi:10.1088/1748-9326/7/1/014023

Takaya K, Nakamura H (2001) A formulation of a phase-independent wave-activity flux for stationary and migratory quasigeostrophic eddies on a zonally varying basic flow. J Atmos Sci 58:608-627

Tebaldi C, Hayhoe K, Arblaster JM, Meehl GA (2006) Going to the extremes: an intercomparison of model-simulated historical and future changes in extreme events. Clim Change 79:185-211

Teng H, Branstator G, Wang H, Meehl GA, Washington WM (2013) Probability of US heat waves affected by a subseasonal planetary wave pattern. Nat Geosci 6:1056-1061. doi:10.1038/ ngeo1988

Thrasher B, Maurer EP, McKellar C, Duffy PB (2012) Bias correcting climate model simulated daily temperature extremes with quantile mapping. Hydrol Earth Sys Sci 16:3309-3314

Turner JK, Gyakum JR (2011) The development of Arctic air masses in Northwest Canada and their behavior in a warming climate. $\mathrm{J}$ Clim 24:4618-4633

Turner JK, Gyakum JR, Milrad SM (2013) A thermodynamic analysis of an intense North American arctic air mass. Mon Weather Rev 141:166-181

van Oldenborgh GJ, Drijfhout S, van Ulden A, Haarsma R, Sterl A, Severijns C, Hazeleger W, Dijkstra H (2009) Western Europe is warming much faster than expected. Clim Past 5:1-12

van Vuuren DP, Edmonds J, Kainuma M, Riahi K, Thomson A, Hibbard K, Hurtt GC, Kram T, Krey V, Lamarque J-F, Masui T, Meinshausen M, Nakicenovic N, Smith SJ, Rose SK (2011) The representative concentration pathways: an overview. Clim Change 109:5-31. doi:10.1007/s10584-011-0148-z

Vavrus SJ, Walsh JE, Chapman WL, Portis D (2006) The behavior of extreme cold air outbreaks under greenhouse warming. Int J Climatol 26:1133

Von Storch H (1999) On the use of "inflation" in statistical downscaling. J Clim 12:3505-3506

Walsh JE, Philips AS, Portis DH, Chapman WL (2001) Extreme cold outbreaks in the United States and Europe, 1948-99. J Clim $14: 2642-2658$

Wang A, Zeng X (2013) Development of global hourly $0.5^{\circ}$ land surface air temperature datasets. J Clim 26:7676-7691. doi:10.1175/JCLI-D-12-00682.1

Wehner MF (2004) Predicted 21st century changes in seasonal extreme precipitation events in the parallel climate model. J Clim 17:4281-4290

Wehner MF (2010) Sources of uncertainty in the extreme value statistics of climate data. Extremes 13:205-217. doi:10.1007/ s10687-010-0105-7

Westby RM, Lee YY, Black RX (2013) Anomalous temperature regimes during the cool season: long-term trends, low-frequency mode modulation, and representation in CMIP5 simulations. J Clim 26:9061-9076

Wexler H (1936) Cooling in the lower atmosphere and the structure of polar continental air. Mon Weather Rev 64:122-136

Wexler H (1937) Formation of polar anticyclones. Mon Weather Rev 65:229-236

Wilks DS (2006) Statistical methods in the atmospheric sciences, 2nd edn. Academic Press, Waltham

Wu Z, Lin HL, Li J, Jiang Z, Ma T (2012) Heat wave frequency variability over North America: two distinct leading modes. J Geophys Res 117:D02102. doi:10.1029/2011JD016908 
Wuebbles D, Meehl G, Hayhoe K, Karl TR, Kunkel K, Santer B, Wehner M, Colle B, Fischer EM, Fu R, Goodman A, Janssen E, Lee H, Li W, Long LN, Olsen S, Seth A, Sheffield J, Sun L (2014) CMIP5 climate model analyses: climate extremes in the United States. Bull Am Meteorol Soc 95:571-583. doi:10.1175/ BAMS-D-12-00172.1

Zhang X, Alexander LV, Hegerl GC, Klein Tank A, Peterson TC, Trewin B, Zwiers FW (2011) Indices for monitoring changes in extremes based on daily temperature and precipitation data. Wiley Interdiscip Rev Clim Change 2:851-870. doi:10.1002/ wcc. 147

Zwiers FW, Zhang X, Feng Y (2011) Anthropogenic Influence on long return period daily temperature extremes at regional scales. J Clim 24:881-892. doi:10.1175/2010JCLI3908.1 